\title{
The new sun-sky-lunar Cimel CE318-T multiband photometer - a comprehensive performance evaluation
}

\author{
África Barreto ${ }^{1,2}$, Emilio Cuevas ${ }^{1}$, María-José Granados-Muñoz ${ }^{3,4}$, Lucas Alados-Arboledas ${ }^{3,4}$, Pedro M. Romero ${ }^{1}$, \\ Julian Gröbner ${ }^{5}$, Natalia Kouremeti ${ }^{5}$, Antonio F. Almansa ${ }^{1,2}$, Tom Stone ${ }^{6}$, Carlos Toledano $^{7}$, Roberto Román ${ }^{7}$, \\ Mikhail Sorokin $^{8}$, Brent Holben ${ }^{8}$, Marius Canini ${ }^{2}$, and Margarita Yela ${ }^{9}$ \\ ${ }^{1}$ Izaña Atmospheric Research Center, Meteorological State Agency of Spain (AEMET), Spain \\ ${ }^{2}$ Cimel Electronique, Paris, France \\ ${ }^{3}$ Department of Applied Physics, University of Granada, Granada, Spain \\ ${ }^{4}$ Andalusian Institute for Earth System Research, IISTA-CEAMA, University of Granada, Junta de Andalucía, Granada, Spain \\ ${ }^{5}$ Physikalisch-Meteorologisches Observatorium Davos and World Radiation Center (PMOD/WRC), Davos, Switzerland \\ ${ }^{6}$ US Geological Survey, Flagstaff, USA \\ ${ }^{7}$ Grupo de Óptica Atmosférica, Universidad de Valladolid, Valladolid, Spain \\ ${ }^{8}$ NASA/Goddard Space Flight Center, Greenbelt, USA \\ ${ }^{9}$ Instrumentation and Atmospheric Research Department, National Institute for Aerospace Technology (INTA), Madrid, Spain
}

Correspondence to: África Barreto (cimel1@aemet.es)

Received: 18 September 2015 - Published in Atmos. Meas. Tech. Discuss.: 28 October 2015

Revised: 22 January 2016 - Accepted: 6 February 2016 - Published: 24 February 2016

\begin{abstract}
This paper presents the new photometer CE318$\mathrm{T}$, able to perform daytime and night-time photometric measurements using the sun and the moon as light source. Therefore, this new device permits a complete cycle of diurnal aerosol and water vapour measurements valuable to enhance atmospheric monitoring to be extracted. In this study we have found significantly higher precision of triplets when comparing the CE318-T master instrument and the Cimel AErosol RObotic NETwork (AERONET) master (CE318AERONET) triplets as a result of the new CE318-T tracking system. Regarding the instrument calibration, two new methodologies to transfer the calibration from a reference instrument using only daytime measurements (Sun Ratio and Sun-Moon gain factor techniques) are presented and discussed. These methods allow the reduction of the previous complexities inherent to nocturnal calibration. A quantitative estimation of CE318-T AOD uncertainty by means of error propagation theory during daytime revealed AOD uncertainties $\left(u_{\mathrm{AOD}}^{\mathrm{D}}\right)$ for Langley-calibrated instruments similar to the expected values for other reference instruments $(0.002-0.009)$. We have also found $u_{\mathrm{AOD}}^{\mathrm{D}}$ values similar to the values reported in sun photometry for field instruments $(\sim 0.015)$. In the case of the night-time period, the CE318-
\end{abstract}

T-estimated standard combined uncertainty $\left(u_{\mathrm{AOD}}^{\mathrm{N}}\right)$ is dependent not only on the calibration technique but also on illumination conditions and the instrumental noise. These values range from $0.011-0.018$ for Lunar Langley-calibrated instruments to $0.012-0.021$ for instruments calibrated using the Sun Ratio technique. In the case of moon-calibrated instruments using the Sun-Moon gain factor method and suncalibrated using the Langley technique, we found $u_{\mathrm{AOD}}^{\mathrm{N}}$ ranging from 0.016 to 0.017 (up to 0.019 in $440 \mathrm{~nm}$ channel), not dependent on any lunar irradiance model.

A subsequent performance evaluation including CE318$\mathrm{T}$ and collocated measurements from independent reference instruments has served to assess the CE318-T performance as well as to confirm its estimated uncertainty. Daytime AOD evaluation, performed at Izaña station from March to June 2014, encompassed measurements from a reference CE318-T, a CE318-AERONET master instrument, a Precision Filter Radiometer (PFR) and a Precision Spectroradiometer (PSR) prototype, reporting low AOD discrepancies between the four instruments (up to 0.006). The nocturnal AOD evaluation was performed using CE318-T- and starphotometer-collocated measurements and also by means of a day/night coherence transition test using the CE318-T mas- 
ter instrument and the CE318 daytime data from the CE318AERONET master instrument. Results showed low discrepancies with the star photometer at 870 and $500 \mathrm{~nm}$ channels $(\leq 0.013)$ and differences with AERONET daytime data $(1 \mathrm{~h}$ after and before sunset and sunrise) in agreement with the estimated $u_{\mathrm{AOD}}^{\mathrm{N}}$ values at all illumination conditions in the case of channels within the visible spectral range, and only for high moon's illumination conditions in the case of nearinfrared channels.

Precipitable water vapour (PWV) validation showed a good agreement between CE318-T and Global Navigation Satellite System (GNSS) PWV values for all illumination conditions, within the expected precision for sun photometry.

Finally, two case studies have been included to highlight the ability of the new CE318-T to capture the diurnal cycle of aerosols and water vapour as well as short-term atmospheric variations, critical for climate studies.

\section{Introduction}

The energy from the sun constitutes the driving force of the Earth's climate, but not all of the solar energy that reaches the top of the atmosphere reaches the surface. In this respect, aerosols play an important role in the Earth's radiation budget, directly modifying the energy balance by the scattering/absorption of the solar radiation, and indirectly through their impact on cloud formation and properties (Foster et al., 2007; Kaufman et al., 2002; Myhre, 2009). There is also a semi-direct aerosol effect associated with the absorption of solar radiation by aerosols which could potentially modify cloud properties (Kaufman et al., 2002). However, the high spatial/temporal variability of aerosols and the high complexity of aerosols in the atmosphere make the task of quantifying their climate effect difficult. Indeed, according to the IPCC report (Stocker et al., 2013), aerosols dominate the uncertainty associated with the total anthropogenic driving of climate change. This report estimated a global and annual direct radiative forcing effect of anthropogenic aerosols of $-0.35 \mathrm{~W} \mathrm{~m}^{-2}$, with an uncertainty ranging from -0.85 to $-0.15 \mathrm{~W} \mathrm{~m}^{-2}$. The total aerosol radiative effect including aerosol-cloud interactions was estimated as a radiative forcing of $-0.9(-1.9$ and -0.1$) \mathrm{W} \mathrm{m}^{-2}$. Notable recent advances in the last decades in the understanding of atmospheric aerosols have substantially reduced the uncertainty in the total direct aerosol effect on the Earth's climate (Myhre, 2009). The combination of aerosol satellite and ground-based measurements have resulted in a remarkably increased knowledge about aerosol geographical distribution, concentration and microphysical properties, but there are still large uncertainties in individual radiative forcing for several of the aerosol components, such as black carbon particles, organic carbon or nitrates (Myhre, 2009). This uncer- tainty reflects how challenging it is to quantify the aerosol radiative forcing and highlights the need to adequately determine the nature and spatial/temporal variability of aerosols on both regional and global scales.

At present, there are several global or regional networks established during the last 2 decades based on measurements at ground level; the globally distributed AErosol RObotic NETwork (AERONET) is one of the most important networks for the monitoring of passive long-term aerosols (Holben et al., 1998, 2001). This global sun photometer network offers aerosol optical, microphysical and radiative properties using the standard sun photometer CE318-N as a reference instrument (hereinafter referred to as CE318-AERONET), in addition to real-time data reception accessible for the scientific community (Holben et al., 2001). Another reference network for aerosol monitoring is the Global Atmosphere Watch (GAW) network, using the Precision Filter Radiometer (PFR) as a reference instrument (Wehrli, 2000, 2005). The PFR instrument was developed by the World Optical Depth Research and Calibration Center (WORCC) that was established in 1996 by the World Meteorological Organization (WMO), assigned as the reference centre for spectral radiometry to determine AOD (WMO, 2003). However, in spite of the high temporal and spectral resolution provided by these networks, the sun photometry provides aerosol information which is restricted to the daylight period and columnaveraged. These are the two most important limitations of solar photometry, which prevent the existence of aerosol observations with the required temporal resolution for climate studies. This problem is especially challenging at highlatitude locations, due to the extended periods of darkness at wintertime, which significantly limits the information we have to better understand this fragile climate system.

Several studies in the literature are focused on the estimation of AOD at night-time by means of star photometry (Ansmann et al., 2001; Herber et al., 2002; Pérez-Ramírez et al., 2008a, 2011; Baibakov et al., 2015). Although this technique is able to determine AOD with similar accuracies to sun photometry (expected errors in AOD of $\sim 0.02$ for $\lambda<800 \mathrm{~nm}$ and $\sim 0.01$ for $\lambda>800 \mathrm{~nm}$ ) (Pérez-Ramírez et al., 2011), the important operational difficulties and the complexities of such large-aperture systems needed to collect the weak star light make stellar measurements still limited in use, especially for large-scale networks such as AERONET. The study developed by Berkoff et al. (2011) was the pioneering work in moon photometry, being the first one to use a modified Cimel sun photometer to obtain night-time AOD measurements with the moon as light source and using a lunar irradiance model to account for the continuous change in the moon's illumination over the moon cycle. Recently, Barreto et al. (2013a, b) presented a new photometer prototype (CE318-U), similar to the CE318-AERONET reference instrument, with a prototype four-quadrant detector able to perform lunar measurements to characterize aerosols and water vapour at night-time. These authors showed that this new 
CE318-U instrument permits a continuous sequence of diurnal aerosol concentrations to be derived in combination with the current CE318-AERONET. This instrument was able to perform nocturnal measurements under a moon illumination greater than $50 \%$, and therefore it was able to cover $50 \%$ of the moon cycle, providing the opportunity to significantly extend the continuity of existing observations.

The use of active remote measurements such as advanced ground-based lidars systems prevents the last two handicaps of sun photometry, providing daytime and night-time information about the atmospheric vertical structure. As a result, this technique has proven to be very effective in the characterization of aerosols in high-latitude regions (Baibakov et al., 2015; Tomasi et al., 2015; Hoffmann et al., 2009). Lidars allow us to determine vertical profiles of aerosol optical properties and estimate some microphysical properties (only using multiwavelength Raman Lidars), but some physical or mathematical constraints are necessary in the inversion algorithm. The synergy between lidar and sun photometers is currently implemented and successfully checked (Fernald, 1984; Klett, 1985; Cuesta et al., 2008; Chaikovsky et al., 2012; Lopatin et al., 2013) to minimize the uncertainties of these assumptions when inverting the lidar signals using the common Klett-Fernald-Sasano technique (Fernald, 1984; Klett, 1985; Sasano et al., 1985). It also serves to reduce uncertainties in the retrieval of microphysical properties using multiwavelength lidars (Pahlow et al., 2006; Tesche et al., 2008). Some examples in the literature of the potential of these combined lidar-photometer observations are the numerical tool LIRIC (LIdar/Radiometer Inversion Code), developed by Chaikovsky et al. (2012), or the GARRLiC (Generalized Aerosol Retrieval from Radiometer and Lidar Combined data) method, introduced by Lopatin et al. (2013) and tested by Wagner et al. (2013) and Granados-Muñoz et al. (2014). More recently, Barreto et al. (2014a) and Baibakov et al. (2015) showed the improvement in the synergetic retrieval of AOD at night-time using a combination of lidar and lunar photometer (CE318-U) measurements in the first case, and by means of lidar and star photometer measurements in the second case.

In this work we present the new photometer CE318-T (Sect. 2), which combines the features of the extensively used CE318-AERONET standard model (Holben et al., 1998) with the ability to perform nocturnal measurements of the prototype CE318-U, described in Barreto et al. (2013a, b). The CE318-T instruments were deployed at Izaña Atmospheric Observatory (IZO) and Granada stations. IZO is a high-altitude site, while Granada is an urban station. These sites are presented in Sect. 3. The instruments, as well as the supporting information used to evaluate the CE318-T performance, and the lunar irradiance model are shown in Sect. 4. The instrument's calibration is described and assessed in Sect. 5.1, where we present four different approaches for CE318-T calibration. The absolute calibration of this instrument is presented as a combination of the usual Lang- ley Method for daytime and the Lunar Langley Method for night-time (Sect. 5.1.1), while the Moon Ratio technique is presented in Sect. 5.1.2 as an alternative technique for nighttime calibration transference using measurements restricted to the night-time period. We have also presented two new techniques to perform the calibration transference from a reference instrument using only daytime measurements: the Sun Ratio method (Sect. 5.1.2), which requires a moon-calibrated reference instrument, and the Sun-Moon gain factor method (Sect. 5.1.3), which only requires a sun-calibrated reference instrument and it is not dependent on any lunar irradiance model. In Sects. 5.2 and 5.3 we detail the methodology to obtain AOD, Angström's exponent (AE) and PWV using CE318-T. Section 6 describes a quantitative estimation of CE318-T AOD uncertainty. In Sects. 7.1 and 7.2 we present the assessment of the Sun Ratio and Sun-Moon gain factor calibration methods. We perform the evaluation analysis of CE318-T AODs in Sect. 7.3, carried out by the comparison of AODs extracted in the daytime period from four different independent instruments (CE318-T master instrument, CE318-AERONET master instrument, PFR and Precision Spectroradiometer - PSR) and, in Sect. 7.4, a similar analysis for the night-time period, using CE318-T measurements with collocated star photometer observations. We have extended the evaluation analysis through a day/night coherence test transition using CE318-AERONET daytime data and CE318-T AOD information (Sect. 7.5). Daytime and night-time CE318-T PWV measurements at IZO were validated against Global Navigation Satellite System (GNSS) and AERONET data in Sect. 7.6. Two demonstration case studies (Sect. 8) showed the ability of the instrument to monitor short-scale atmospheric processes. Finally, the main conclusions of the present study are summarized in Sect. 9.

\section{Instrumentation - the new sun-sky-lunar Cimel CE318-T}

The new sun-sky-lunar Cimel CE318-T photometer has been developed by the French company Cimel Electronique, improving the tracking precision in order to perform both daytime and night-time (lunar) measurements and providing additional and enhanced operational functionalities compared with the standard sun photometer CE318-AERONET, extensively described in Holben et al. (1998). The CE318-T is based on a new control unit and a new four-quadrant system in the sensor head.

The CE318-T is based on the former prototype CE318-U, described in Barreto et al. (2013a, b), which presents higher signal-to-noise ratios (better than $60 \mathrm{~dB}$ ) to capture not only the daytime radiation from the sun but also the limited energy during night-time reflected by the moon, and therefore is able to provide valuable information of aerosols and water vapour at night-time.

Similarly to the standard CE318-AERONET, the new CE318-T performs measurements at an approximate field of 
view of $1.29^{\circ}$ at 10 nominal wavelengths of $1020,937,870$, $675,500,440,380$ and $340 \mathrm{~nm}$, using a silicon photodiode detector, as well as additional measurements at 1020 and $1640 \mathrm{~nm}$ using an InGaAs (indium gallium arsenide) detector. Due to the low signal in the UV channels at night, AOD cannot be obtained and therefore UV information is restricted to the daylight period.

This new instrument performs three different measurement types: spectral direct-sun and direct-moon irradiance measurements to obtain aerosol and water vapour content, and spectral sky radiances to infer aerosol properties from inversion during daytime period. This is the reason for applying the term "triple" to this new Cimel photometer. As in the standard AERONET version, the CE318-T takes a sequence of three measurements (triplet) every $30 \mathrm{~s}$ at each wavelength. The triplet value is defined as the maximum minus minimum divided by the mean value of these three consecutive measurements. It means that each triplet represents the normalized range of these three consecutive measurements. At this moment, the triplet information is used to detect and remove clouds as well as to check the instrument's stability until a new operative cloud screening is applied.

Among the new features of this new instrument (CE318-T) we highlight the following.

- The CE318-T has a new tracking system. The new fourquadrant detector in the sensor head is designed to track both the sun and the moon. The tracking firmware has been optimized to provide robust moon tracking, even in the presence of nearby clouds or night-time light pollution. The new control box uses microstepping technology to control the robot. All movements are smoothed and full step shocks are eliminated. The pointing resolution is improved to $0.003^{\circ}$ on both axes. The robot is held in position between each movement to avoid unwanted movements caused by wind or cables. With all of these new features, the new tracking system is expected to improve measurement precision in the daytime compared to the CE318-AERONET version.

- The control box is equipped with a powerful microprocessor, an internal $4 \mathrm{Mb}$ flash memory and an on board SD card that avoids any loss of data.

- A single powerful firmware includes all usual scenarios for any of the four CE318-T models: standard, polarized or sea prism. It also includes new scenarios like the hybrid scenario (for sky measurements with larger scattering angles) and curvature cross from \pm 3 to $\pm 7.5^{\circ}$ (for improved cloud screening in the daytime).

- Data are stored and transferred with 32 bits. As a result, previous digital gains have been eliminated.

- The instrument is designed to run (both daytime and night-time) with its usual solar panel, for better protection against lightning effects. The internal battery has been suppressed in order to simplify operations, and the power consumption has been reduced. The local interface is improved with a robust touch keyboard and a large backlit graphic LCD display.

- The atmospheric pressure is measured in each group of scenarios by a barometer integrated in the connector panel. The control box is also equipped with inputs to connect a pyranometer and is designed to support a SDI12 bus.

- The control box is equipped with a GPS receiver for improved time synchronization and automatic localization.

- It supports communications through local serial, local USB and local radio, and remotely through a GPRS mobile phone with automatic transfer via file transfer protocol or a website. For isolated locations, it supports communication through satellite data collection platform (DCP) with fully automated DCP configuration.

\section{Measurement sites}

The Izaña Atmospheric Observatory (http://izana.aemet.es) is a high mountain atmospheric monitoring station located at $2373 \mathrm{~m}$ a.s.l. in Tenerife, Canary Islands, Spain $\left(28.31^{\circ} \mathrm{N}\right.$; $\left.16.49^{\circ} \mathrm{W}\right)$. It is managed by the Izaña Atmospheric Research Center (IARC) from the State Meteorological Agency of Spain (AEMET). High-quality atmospheric measurements are carried out at IZO since it is normally located above a strong and quasi-permanent subsidence temperature inversion typical of the subtropical regime, which prevents pollution from lower parts of the island. Clear skies and high atmospheric stability make IZO a suitable site for atmospheric monitoring and calibration activities under free-tropospheric conditions. Moreover, this station also allows us to measure under Saharan Air Layer (SAL) conditions (Rodríguez et al., 2011, 2015; Cuevas et al., 2013, 2015; Barreto et al., 2014b), which is an advantage for characterizing photometers in a wide range of $\mathrm{AOD}$ and $\mathrm{AE}$ values. This station is a member of the WMO-GAW programme and is one of the two directsun calibration sites of the AERONET network (Holben et al., 1998). IZO is also a WMO Commission for Instruments and Methods of Observation (CIMO) Testbed for Aerosols and Water Vapor Remote Sensing Instruments.

Granada station $\left(37.16^{\circ} \mathrm{N}, 3.60^{\circ} \mathrm{W} ; 680 \mathrm{ma.s.l}\right)$ is an EARLINET (Pappalardo et al., 2014) and AERONET station, managed by the Atmospheric Physics Group (GFAT) at the Andalusian Institute for Earth System Research (IISTACEAMA). The station is located in the south-east of Spain in a non-industrialized metropolitan area surrounded by mountains. Its aerosol climatology is dominated by Atlantic air masses, usually associated with low aerosols conditions, air masses from Europe and the Mediterranean basin, with more influence of anthropogenic particles, and also an important 
influence of mineral dust from the African continent (Valenzuela et al., 2012) detected in lofted aerosol layers in the free troposphere that can affect the boundary layer (GuerreroRascado et al., 2009; Navas-Guzmán et al., 2013; BravoAranda et al., 2015). The experimental site is also affected by anthropogenic particles and dust resuspension from local aerosol sources (Lyamani et al., 2010, 2012; Titos et al., 2014).

\section{Instruments and supporting information}

\subsection{Independent AOD measurements}

Several CE318-T instruments have been installed at IZO since 2013. The master instrument has been in operation since December 2013, but only information from March 2014 to present can be used to characterize its performance. Another instrument, referred to as secondary, was installed from March to June 2014. Coincident information extracted from these paired instruments has been used to validate the new calibration transference technique developed for CE318T. Later, this secondary instrument was sent to Granada station, where it was in operation during August 2014.

In this work we have used ancillary data collected at IZO from Cimel AERONET instrument. AERONET version 2 Level 2.0 AOD data were retrieved from the IZO master no. 244 (http://aeronet.gsfc.nasa.gov). This information is quality-assured following the AERONET protocol (Holben et al., 1998). We have also used AERONET version 2 Level 1.5 data, not quality-assured for data collected in 2015 .

A four-wavelength GAW PFR developed by the WORCC of the PMOD World Radiation Center (http://www. pmodwrc.ch/worcc/index.html) has been in operation at IZO since July 2001. This instrument provides AOD at 367.6, $412.1,501.0$ and $863.1 \mathrm{~nm}$. The PFR instrument of IZO is directly linked with the WORCC-WMO AOD reference triad of PFRs that operates at WORCC. During April, May and June 2014, a PSR prototype (Gröbner et al, 2012) was running at IZO, providing coincident measurements with PFR, CE318-AERONET and CE318-T. This spectroradiometer is designed to measure direct solar irradiance between approximately 300 and $1020 \mathrm{~nm}$, with a resolution varying between 1.4 and $6 \mathrm{~nm}$ over the wavelength range.

The final part of the AOD evaluation procedure involves CE318-T measurements performed at Granada station. Nighttime AOD information was obtained using the EXCALIBUR star photometer (Astronómica S. L.) which belongs to IISTA-CEAMA. More details of this system can be found in Pérez-Ramírez et al. (2008b, 2012a). This instrument acquires direct star irradiances at 380, 436, 500, 670, 880,940 and $1020 \mathrm{~nm}$ using a Schmid-Cassegrain telescope and a charge-coupled device camera as a detector device. Periodical calibrations of the star photometer are performed at the high mountain station Calar Alto $\left(37.2^{\circ} \mathrm{N}, 2.5^{\circ} \mathrm{W}\right.$; $2168 \mathrm{~m}$ a.s.l.), following the calibration technique described in Pérez-Ramírez et al. (2011). The instrument has been used both to follow day-night-time AOD evolution (PérezRamírez et al., 2012b) and to retrieve aerosol microphysical properties (Pérez-Ramírez et al., 2015).

Finally, we have used vertical aerosol backscatter information in this work extracted from a Micropulse Lidar (MPL), MPL-3 (SES Inc., USA) system (Spinhirne et al., 1995). This instrument has been operating at Santa Cruz de Tenerife station $\left(28.5^{\circ} \mathrm{N}, 16.2^{\circ} \mathrm{W} ; 52 \mathrm{~m}\right.$ a.s.l.) since January 2005 and it is currently in operation within the NASA/MPLNET network (http://mplnet.gsfc.nasa.gov). It is co-managed by the National Institute for Aerospace Technology (INTA, Spain) and the IARC. Further information about MPL and the calibration techniques can be found in Campbell et al. (2002) and in Welton and Campbell (2002).

\subsection{Independent PWV measurements}

For the PWV intercomparison study we have used, in addition to AERONET level 2.0 PWV measurements, a LEICA GRX1200GGPRO GNSS receiver which belongs to the Spanish National Geographical Institute (IGN), and has been operating at IZO (IZAN station, IERS code 31309M002) within the European Reference Frame network (EUREF, Bruyninx, 2004) since July 2008. This instrument is part of the EUMETNET (Network of European Meteorological Services) GNSS water vapour programme (E-GVAP). It provides instantaneous zenith total delay (ZTD) values every $15 \mathrm{~min}$ (GNSS ultra-rapid orbits) by applying the Bernese software version 5.0 (Dach et al., 2007); meanwhile, the zenith hydrostatic delay (ZHD) is calculated at IZO with the actual surface pressure at the station, measured with a high-precision SETRA 470 barometer. The methodology to convert ZWD data to PWV is described in Romero et al. (2009). We have used $1 \mathrm{~h}$ resolution instantaneous ZTD postprocessed values (GNSS precise orbits). The GNSS station at Granada (Granada station, EUREF code 13459M002), managed by the Instituto Andaluz de Geofísica, is equipped with a LEICA GRX1200PRO receptor. Only GNSS ultra-rapid orbits PWV data are available at Granada for the time period studied in this paper.

\subsection{Lunar irradiance model}

Barreto et al. (2013a) described that in lunar photometry it is necessary to use a lunar irradiance model to compute the moon's extraterrestrial irradiance $\left(I_{0}\right.$, Eq. (4) of Barreto et al., 2013a) to predict the changes in this quantity through the night. The Robotic Lunar Observatory (ROLO) at the United States Geological Survey (USGS) in Flagstaff, Arizona, has developed a model for the lunar spectral irradiance (Kieffer and Stone, 2005) as part of a NASA-funded effort for onorbit calibration of remote sensing satellite instruments. The ROLO model can provide the exoatmospheric lunar irradiance for any given location and time within its valid geome- 
try range, and for any instrument's spectral response within its valid wavelength range. The model is based on fitting thousands of lunar measurements acquired over more than 8 years with the ground-based ROLO telescopes in 32 wavelength bands from 350 to $2450 \mathrm{~nm}$. Kieffer and Stone (2005) found band-averaged residuals $\sim 1 \%$ from fitting the ROLO data set with a function of only the geometric variables of phase angle and the sub-solar and sub-observer points on the moon, i.e. the lunar librations. This value is a measure of the precision of ROLO model predictions of the lunar irradiance over its full range of geometries. For a given night of lunar photometer measurements, the relative prediction precision is well below $1 \%$. In this study, ROLO model computations of $I_{0}$ were provided by the USGS team, as part of their support to AERONET. We have also used the algorithm described in Barreto et al. (2013a), which has been proven to provide similar results to the USGS ROLO.

\section{Aerosols and PWV determination using the new CE318-T}

\subsection{Instrument's calibration}

Similarly to the standard CE318-AERONET calibration, the CE318-T calibration during the daytime period can be performed applying the standard Langley-Bouguer calibration at high mountain stations for direct-sun measurements, using an integrating sphere for sky radiances' calibration, or by means of a cross-calibration transference technique. These methods are extensively described in Holben et al. (1998).

In the case of the night-time, the absolute CE318-T calibration can be performed following the Lunar Langley Method (Barreto et al., 2013a), or by means of calibration transference using the Ratiomoon method, previously published by Barreto et al. (2013a). In both cases, these calibration techniques require nocturnal measurements, and therefore they are subject to the inherent inconveniences associated with the lunar cycle (changing illumination conditions and only a few days around full moon to perform the instrument calibration). In this work we present two new techniques with the aim of overcoming these calibration problems at night-time: Ratio ${ }_{\text {sun }}$ and Sun-Moon gain factor techniques. These techniques involve the calibration transference from a reference instrument using only daytime measurements.

\subsubsection{Absolute calibration at night-time}

According to Barreto et al. (2013a), the absolute calibration can not be performed using the common Langley-Bouguer technique. The reason is that, unlike the sun, the moon is a highly variable source which changes continuously with the lunar-viewing geometry. Thus, Barreto et al. (2013a) developed the Lunar Langley Method modifying the usual Langley technique to be applied under variable illumination con- ditions, avoiding the determination of the instrument calibration every night. In this method the calibration coefficient for the instrument $i$ (master with the superscript " $\mathrm{M}$ " or secondary with the superscript " $\mathrm{S}$ ") can be expressed as

$V_{0, \lambda}^{i}=I_{0, \lambda} \cdot \kappa_{\lambda}^{i}$,

where $I_{0, \lambda}$ is the extraterrestrial irradiance in a certain channel with a central wavelength at $\lambda$, and $\kappa_{\lambda}^{i}$ is the instrument's calibration constant, which depends on the instrument features. $I_{0, \lambda}$ is calculated using the ROLO model (Kieffer and Stone, 2005). $\kappa_{\lambda}$ constant strictly accounts for the instrument's photometric responsivity and any residual systematic offset difference between ROLO-predicted $I_{0, \lambda}$ and the real exoatmospheric irradiance.

\subsubsection{Calibration transference at night-time: Ratio $_{\text {moon }}$ and Ratio sun $_{\text {methods }}$}

Barreto et al. (2013a) found that CE318-U photometer calibration can also be attained by transference from a calibrated instrument (using the ratio of moon measurements, hereinafter called Moon Ratio technique or Ratio ${ }_{\text {moon }}$ ). Following these authors, CE318-T night-time calibration can be performed applying this technique of nocturnal ratios. However, taking the advantage of the increased CE318-T digital resolution and the simplicity that supposes the use of fixed internal gains, it is also possible to establish a new way to transfer the moon absolute calibrations from a CE318-T master instrument to an uncalibrated secondary CE318-T instrument using only daylight period measurements. In this case, we can consider the ratio master-secondary of averaged coincident raw data (digital counts or DCs) measured in the daytime $\left(\overline{\mathrm{DC}_{\mathrm{D}}^{i}}\right)$ and in the night-time $\left(\overline{\mathrm{DC}_{\mathrm{N}}^{i}}\right)$ to be similar. Therefore,

$V_{0, \lambda}^{\mathrm{S}}=V_{0, \lambda}^{\mathrm{M}} \cdot \frac{\overline{\overline{\mathrm{DC}}}}{\overline{\mathrm{DC}_{\mathrm{N}}^{\mathrm{M}}}} \sim V_{0, \lambda}^{\mathrm{M}} \cdot \frac{\overline{\mathrm{DC}_{\mathrm{D}}^{\mathrm{S}}}}{\overline{\mathrm{DC}_{\mathrm{D}}^{\mathrm{M}}}}$,

with $\frac{\overline{\mathrm{DC}_{\mathrm{D}}^{\mathrm{S}}}}{\overline{\mathrm{DC}_{\mathrm{D}}^{\mathrm{M}}}}=$ Ratio $_{\text {sun. }}$. This new calibration method is called the Sun Ratio technique and avoids the use of nocturnal coincident measurements between master and secondary measurements (or Ratio ${ }_{\text {moon }}$ ), which are affected by higher uncertainties and have to meet restrictive criteria about moon illumination. Thus, the calibration transference using the Sun Ratio makes the calibration of CE318-T instruments simpler and easier. It implies that, combining Eqs. (1) and (2), once a master instrument is moon-calibrated using the Lunar Langley Method $\left(\kappa_{\lambda}^{\mathrm{M}}\right)$, it is possible to find the spectral calibration constants for the secondary $\left(\kappa_{\lambda}^{\mathrm{S}}\right)$ by means of coincident daytime measurements:

$\kappa_{\lambda}^{\mathrm{S}}=\kappa_{\lambda}^{\mathrm{M}} \cdot$ Ratiosun, $\lambda$.

Implicit in this assumption is the fact that the lunar irradiance model $\left(I_{0, \lambda}\right)$ is the same for master and secondary coincident measurements and also the fact that the Ratio moon 


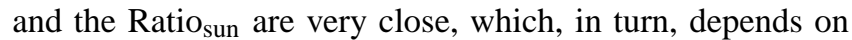
the value of the fixed resistance gains installed in each instrument. These resistances link detector voltages and output voltages, with a different configuration (in parallel or in series) depending on the type of measurement (sun mode or moon/sky mode). As a result, the goodness of the Eq. (3) depends on how uncertain the assigned value of these resistances is $(\sim 1 \%$, given by the manufacturer), and the variability of these values between different instruments.

\subsubsection{Calibration at night-time using an integrated sphere: the Sun-Moon gain factor method}

A fourth method for CE318-T calibration exists, based on previous works developed by Berkoff et al. (2011) and Barreto et al. (2013a), which implies the direct transference of daytime calibration to night-time through the estimation of the different amplification used between sun and moon measurements. It is important to note that the direct-sun and the direct-moon measurements are always performed with the same optical components, so that the only difference between them is the electronic gain or amplification. This amplification can be estimated in laboratory by means of the ratio of moon and sun measurements $\left(\frac{\overline{D_{\mathrm{N}}}}{\overline{\mathrm{CC}_{\mathrm{D}}}}\right)$ using an integrating sphere as light source. In that case, the CE318-T output signal ratio equals the gain ratio (Li et al., 2008). Following this idea, it is possible to estimate night-time $\kappa_{\lambda}$ using Eq. (4).

$\kappa_{\lambda}=\frac{V_{0, \lambda}}{E_{0, \lambda}} \cdot G$

In this equation $V_{0, \lambda}$ represents the daytime calibration for each channel, $E_{0, \lambda}$ is the extraterrestrial solar irradiance and $G$ is the amplification between daytime and night-time measurements.

This Sun-Moon gain factor method is simpler than the previous techniques because it is not dependent on the ROLO model and it only requires the daytime calibration and $G$ determination in the laboratory for $\kappa_{\lambda}$ estimation, which can be easily implemented in the routine sphere calibration process in AERONET network.

\subsection{AOD and AE determination}

Once night-time $\kappa_{\lambda} \mathrm{S}$ are known, it is possible to determine instantaneous AOD from each individual measurement:

$\operatorname{AOD}_{\lambda}=\frac{\ln \left(\kappa_{\lambda}\right)-\ln \left(\frac{V_{\lambda}}{I_{0, \lambda}}\right)-m_{\mathrm{atm}}(\theta) \cdot \tau_{\mathrm{atm}, \lambda}}{m_{\mathrm{a}}(\theta)}$.

The subscript "atm" accounts for air mass and optical depth of all atmospheric attenuators with the exception of aerosols. This term includes the contribution of Rayleigh, $\mathrm{O}_{3}$ and $\mathrm{NO}_{2}$ optical depths, calculated using the same equations and resources as AERONET version 2. Atmospheric pressure has been estimated using the common hydrostatic equation because the information from the CE318-T-integrated barometer was not available for the time period used in this study.

Since AE is a measure of the wavelength dependence of the AOD (Angström, 1929), it is a qualitative indicator of aerosol particle size (Kaufman et al., 1994) and useful to discriminate different atmospheric aerosol types. This parameter is usually retrieved using AOD within the spectral range between 870 and $440 \mathrm{~nm}$. We can obtain AE using the following equation:

$\ln \left(\mathrm{AOD}\left(\lambda_{j}\right)\right)=\ln (\beta)-\mathrm{AE} \cdot \ln \left(\lambda_{j}\right)$.

\subsection{PWV determination}

The Beer-Lambert-Bouguer law must be modified in those spectral regions affected by strong spectral variation of molecular absorption. We do this taking into account the water vapour transmittance: $T_{\mathrm{w}, \lambda}$ (Schmid et al., 1996). As Bruegge et al. (1992) and Halthore et al. (1997) showed, $T_{\mathrm{w}, \lambda}$ presents a exponential dependence with PWV:

$T_{\mathrm{w}, \lambda}=\exp \left(-a\left(m_{\mathrm{w}}(\theta) \cdot \mathrm{PWV}\right)^{b}\right)$.

As shown by Barreto et al. (2013b) for the night-time period, the " $a$ " and " $b$ " constants can be determined by fitting the simulated $T_{\mathrm{w}, \lambda}$ by a radiative transfer model for a specific filter function vs. the PWV. Hence, PWV is obtained using the following expression:

$\mathrm{PWV}=\frac{1}{m_{\mathrm{W}}} \cdot\left\{\frac{1}{a} \cdot\left[\ln \left(\frac{I_{0, \lambda}}{V_{\lambda}}\right)+\ln \left(\kappa_{\lambda}\right)-m_{\mathrm{R}} \cdot \tau_{\mathrm{R}, \lambda}-m_{\mathrm{a}} \cdot \mathrm{AOD}_{\lambda}\right]\right\}^{\frac{1}{b}}$.

In this equation, $m_{\mathrm{w}}$ represents the water vapour optical mass, $m_{\mathrm{R}}$ is the Rayleigh optical mass and $\tau_{\mathrm{R}, \lambda}$ is the Rayleigh optical depth within water vapour absorption band. All these values have been obtained using AERONET version 2 references. $I_{0, \lambda}$ is obtained from the ROLO lunar irradiance model, AOD in this spectral region is obtained by extrapolation of AOD at 870 and $440 \mathrm{~nm}$ and " $a$ " and " $b$ " constants are obtained by simulation of water vapour transmittances using the radiative code MODTRAN 4.0 (Berk et al., 1999) ( $a=0.732$ and $b=0.611)$.

\section{AOD combined standard uncertainty estimation}

In order to perform a quantitative estimation of the uncertainty involved in AOD retrieved by the CE318-T, we have followed the uncertainty propagation procedure described by the Joint Committee for Guides in Metrology (JCGM, 2008). Equation (9) shows the estimated combined standard uncertainty in AOD $\left(u_{\mathrm{AOD}}\right)$ considering that the inputs $\left(V_{0}, V\right.$ and $m$ ) are not correlated. It is calculated using summation in quadrature of each term $u_{x i}$, which represents the standard uncertainty associated with each input. For the sake of brevity, wavelength dependence on these inputs has not been included.

$u_{\mathrm{AOD}}=\sqrt{\frac{1}{m^{2}} \cdot\left[\left(\frac{\delta \mathrm{AOD}}{\delta V_{0}}\right)^{2} \cdot u^{2}\left(V_{0}\right)+\left(\frac{\delta \mathrm{AOD}}{\delta V}\right)^{2} \cdot u^{2}(V)+\left(\frac{\delta \mathrm{AOD}}{\delta m}\right)^{2} \cdot u^{2}(m)\right]}$ 
For the daytime period, we can consider the instrumental uncertainty negligible due to electro-optical precision (Holben et al., 1998) and due to air mass calculation. Consequently, the uncertainty associated with the calibration term $u\left(V_{0}\right)$ is much larger than the uncertainty associated with the other terms. As a result, we can estimate the uncertainty in AOD during the daytime $\left(u_{\mathrm{AOD}}^{\mathrm{D}}\right)$ as a function of the error of the zero air mass term modulated by the air mass:

$u_{\mathrm{AOD}}^{\mathrm{D}}=\frac{1}{m} \cdot \frac{u\left(V_{0}\right)}{V_{0}}$.

As Holben et al. (1998) and Eck et al. (1999) suggested, the combined standard uncertainty of atmosphere, instrument noise and calibration in CE318-AERONET instruments can be inferred by means of the coefficient of variation (CV) of several $V_{0}$ values obtained at a reference station such as Mauna Loa. They found relative uncertainties for reference instruments better than $0.2-0.5$ and $\sim 1.5 \%$ for field instruments in the visible and the near-infrared (nIR) range (Eck et al., 1999; Schmid et al., 1999). This yields an uncertainty due to calibration $\left(u\left(V_{0}\right)\right)$ between 0.002 and 0.005 for reference instruments and $\sim 0.015$ for instruments calibrated by means of intercomparison techniques. Following Eck et al. (1999) and Toledano et al. (2007), it is necessary to include the errors associated with the estimation of Rayleigh optical depth and gaseous absorptions. In the case of CE318-T in the daytime period, we also expect negligible instrument uncertainty $u(V)$ (since dark current and triplets are considerably low) as well as similar estimations for Rayleigh and gases' optical depths. Assuming the values proposed by Eck et al. (1999), a total AOD uncertainty $\left(u_{\text {AOD }}^{\mathrm{D}}\right)$ of $\sim 0.002-0.009$ is estimated for reference instruments, and $\sim 0.010-0.021$ for field instruments. Daytime calibration uncertainty due to Langley and intercomparison procedures are also expected to be similar for CE318-T and CE318-AERONET. These assumptions will be discussed in Sect. 6.1.

In the case of night-time measurements, taking Eq. (1) into account, an alternative form of Eq. (9) is required, including three additional terms: two terms attributed to the contribution of $u(V)$ and the uncertainty in the ROLO model $\left(u\left(I_{0}\right)\right)$, and another term which includes the correlation coefficient $r$ (often called covariance term) of the correlated inputs $\kappa$ and $I_{0}$ (Eq. 11). Please note that the term $u(\kappa)$ corresponds to the uncertainty due to calibration, and it is similar to the calibration term involved in Eq. (10) for daytime measurements $\left(u\left(V_{0}\right)\right.$ in this case).

$$
\begin{aligned}
u_{\mathrm{AOD}}^{N}{ }^{2} & =\frac{1}{m^{2}}\left(\frac{u^{2}(\kappa)}{\kappa^{2}}+\frac{u^{2}\left(I_{0}\right)}{I_{0}^{2}}+\frac{u^{2}(V)}{V^{2}}\right) \\
& +\frac{2}{m^{2}} \cdot r_{\kappa, I_{0}} \cdot\left(\frac{\delta A O D}{\delta \kappa}\right) \cdot\left(\frac{\delta A O D}{\delta I_{0}}\right) \cdot u(\kappa) \\
& \cdot u\left(I_{0}\right) \sim \frac{1}{m^{2}}\left(\frac{u^{2}(\kappa)}{\kappa^{2}}+\frac{u^{2}\left(I_{0}\right)}{I_{0}^{2}}+\frac{u^{2}(V)}{V^{2}}\right)
\end{aligned}
$$

Although the existence of a correlation between $\kappa$ and $I_{0}$ can be anticipated, the covariance term is expected to be near to 0 . The reason for neglecting this term is the low impact of $I_{0}$ systematic uncertainties on $\kappa$ during the Langley period $(\leq 2 \mathrm{~h})$. In any case, considering these two magnitudes are inversely correlated (negative covariance), by neglecting this term, we are obtaining a conservative estimate of the total uncertainty for the night-time period.

Equation (11) presents a combined uncertainty in AOD measurements at night-time related to the random uncertainties in the calibration process as a result of the statistical dispersion estimation $(u(\kappa))$, in addition to the systematic uncertainties due to ROLO estimations $\left(u\left(I_{0}\right)\right)$ and instrument uncertainty $(u(V))$. Kieffer and Stone (2005) estimated a relative accuracy of this model $\leq 1 \%$, and therefore we expect an additional error in computed AOD of $\leq 0.01$. The term in Eq. (11) associated with the instrument calibration can be obtained, similarly to the daytime period, by means of $\mathrm{CVs}$ of the $\kappa \mathrm{s}$ obtained from Lunar Langley-calibrated instruments. The estimate of calibration uncertainty at nighttime for field instruments can be performed by analysing the difference between sun and moon ratios in the case of instruments calibrated using the Moon Ratio technique. An additional error in AOD determination must be included when the Sun Ratio technique is applied. This term is dependent on the precision in the measurement of the internal resistance gains which relate the sun and moon/sky scenarios, and therefore the Ratio ${ }_{\text {sun }}$ and the Ratiomoon values, with each other. In the case of instruments calibrated using the new Sun-Moon gain factor technique, $u(\kappa)$ has the contribution of $u\left(V_{0}\right), E_{0}$ and $G$ calculation. We estimate and discuss these nocturnal instrument calibration uncertainties for field instruments in Sect. 6.2.

The last term in Eq. (11) represents the uncertainty due to instrument precision. This term will be determined in Sect. 6.1 using the normalized range of three consecutive measurements (triplets), in the same way that normalized standard deviations or CVs are used to determine $u(\kappa)$. In our case, since we are working with a set of data with just three measurements, normalized range and normalized standard deviation of triplets are similar quantities. We have empirically determined that they differ by a factor of 2 (normalized range is $\sim 2$ times the normalized standard deviation).

Finally, it is important to highlight that these errors are modulated by the air mass term, and therefore all these expected values are the maximum AOD errors at $m=1$ (for so- 
lar noon and highest moon elevation conditions), and are reduced by a factor of $1 / \mathrm{m}$ as the zenith angle becomes higher, with a minimum at sunset and sunrise in the daytime, and at moonrise and moonset at night-time.

\section{1 $u_{\text {AOD }}$ estimation for reference instruments}

Firstly, we have estimated the uncertainty in calibration for reference instruments (Langley-calibrated). To do this, we computed at IZO the spectral calibration coefficients $V_{0, \lambda}$ for daytime and the calibration constant $\kappa_{\lambda}$ for night-time for the CE318-T master instrument using the Langley-Bouguer technique and the Lunar Langley Method from the average of 20 days (from February to May 2014) and 6 nights (March to June 2014), respectively. These days and nights were affected by low and quite stable aerosol loads. CV for daytime Langley calibration is $\leq 0.31 \%$, similar to those presented in Holben et al. (1998) for Mauna Loa reference sun photometers. It demonstrates that we can consider the same calibration uncertainty for CE318-T and CE318-AERONET Langley-calibrated instruments during the daytime, as suggested previously. For the night-time, $\mathrm{CV}$ s range from 0.39 to $0.78 \%$ for visible channels, to values of 0.73 and $1.24 \%$ for 1020 and $1640 \mathrm{~nm}$, respectively. It leads to an uncertainty calibration estimation of $0.004-0.008$ for visible channels and 0.007-0.014 for near-IR channels in the case of reference instruments. According to Eq. (11), a value of 0.01 must be added due to uncertainties in the ROLO irradiance model and also a value of $u(V)$ as a result of instrumental uncertainties.

Secondly, a comparison analysis on the triplets measured by two master instruments installed at IZO, the CE318-T and the CE318-AERONET, has been performed in order to check the performance of the new CE318-T tracking system, as well as to estimate the instrument precision term $(u(V))$ in Eq. (11). For this study AERONET level 1.5 triplets have been used. Only very stable aerosol conditions have been chosen to analyse triplets variability, selecting a set of 23 days (between February and March 2015) characterized by low AOD at $500 \mathrm{~nm}$ values $(\leq 0.02)$. We can see significantly lower triplet variability values at all wavelengths for CE318$\mathrm{T}$ compared to the previous CE318-AERONET in Fig. 1a. The higher variability in CE318-AERONET $1020 \mathrm{~nm}$ channel indicates a possible problem affecting this channel, in addition to the expected uncertainties due to the lack of temperature correction in this level 1.5 data version. The rest of the channels showed CE318-T mean triplet values between 112 and $172 \%$ lower than those values for CE318-AERONET. It indicates the better performance of this new tracking system, pointing to an improved precision of CE318-T compared to previous sun photometer versions. However, it is fair to admit that a final confirmation of the CE318-T precision improvement must be given after using data from several instruments.

We have also analysed the variability of CE318-T triplets at night-time, including a set of 7 nights near full moon and 5 nights near quarter moon between January and April
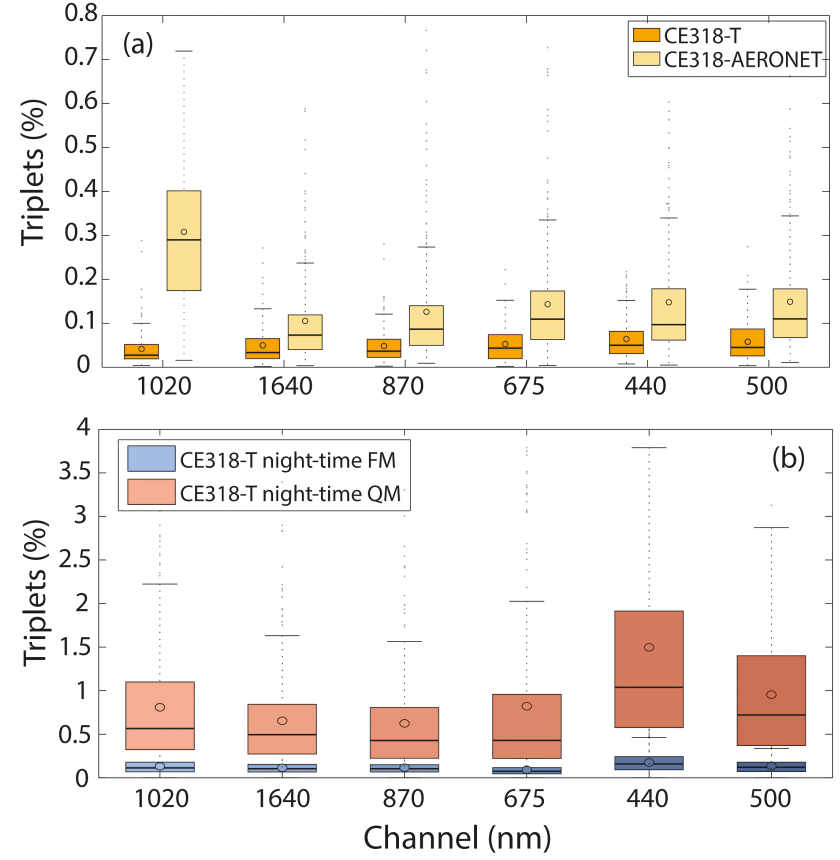

Figure 1. Box plot of triplets (in \%) measured at IZO for (a) CE318$\mathrm{T}$ and CE318-AERONET in a daytime period of 23 days from February and March 2015, with pristine conditions (AOD at $500 \mathrm{~nm}$ $\leq 0.02$ ), and (b) for CE318-T in a night-time period of 7 nights near full moon (FM, in blue) and 5 nights near quarter moon (QM, in red) between January and April 2015. In this figure, circles represent the mean value, while the horizontal line inside each box is the median value.

2015 (Fig. 1b). Generally, triplets measured under near full moon conditions are lower than $0.2 \%$, similar to the CE318AERONET daytime triplet values. For low illumination conditions, triplets are higher, up to $1 \%$ in all channels with the exception of $440 \mathrm{~nm}$, with triplets up to $2 \%$. Thus, the additional uncertainty due to measurement errors is dependent on illumination conditions and is half of the triplets' normalized range (an estimation of the normalized standard deviation), with a value $\leq 0.001$ for near full moon and 0.005 for near quarter moon ( 0.01 in the case of the $440 \mathrm{~nm}$ channel). With this information we could estimate that the combined AOD standard uncertainty at night-time for a reference instrument is $0.011-0.013(0.012-0.014)$ in the case of visible channels and full moon (quarter moon) conditions, with values up to 0.016 in the $440 \mathrm{~nm}$ channel at higher phase angles. For near-IR wavelengths we have obtained a combined standard uncertainty estimation in AOD, ranging from 0.012 to 0.017 for full moon conditions and between 0.013 and 0.018 for quarter moon.

\section{2 $u_{\mathrm{AOD}}$ estimation for field instruments}

In order to estimate the combined standard uncertainty in AOD measurements for CE318-T field instruments, we per- 

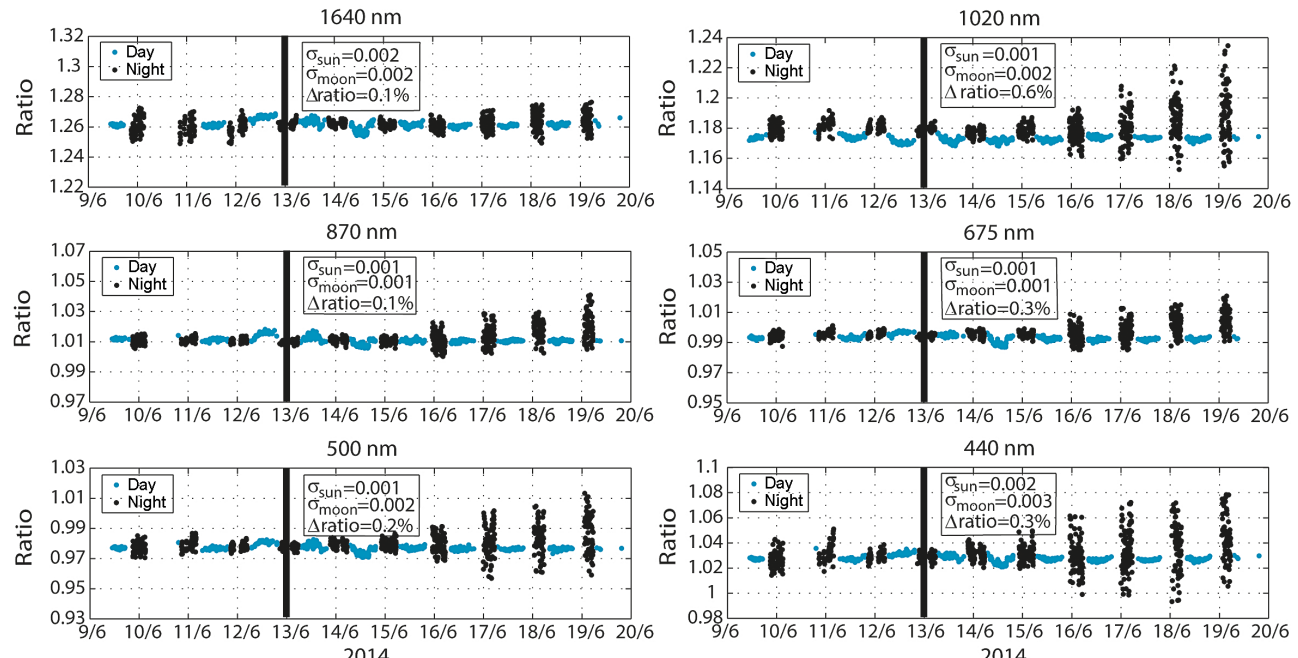

Figure 2. Ratio of simultaneous master/secondary signals at IZO performed on 11 consecutive days and 10 consecutive nights in June 2014. The vertical black line corresponds to the coincidence of full moon conditions. Standard deviations $(\sigma \mathrm{s})$ and ratio differences $(\Delta$ ratio) are depicted in each figure for ratios of sun midday and \pm 1 night near full moon events.

formed the calibration of a secondary instrument using coincident master/secondary measurements taken under stable atmospheric conditions on 22 consecutive days (from 9 to 30 June 2014) and 10 consecutive nights (from 9 to 20 June 2014) in order to ensure the validity of Eq. (3) for $\kappa_{\lambda}^{\mathrm{S}}$ estimation. The different spectral ratio in this lunar cycle at each channel was calculated to show the ratio variability in daytime and night-time conditions throughout the lunar cycle (Fig. 2 for 11 consecutive days and 10 consecutive nights). We observe that the ratio of measurements during day and night is quite similar in the case of high moon illumination conditions, and the ratio performed using nocturnal measurements presents higher dispersion with decreasing illumination of the moon. We have found similar standard deviations ( $\sigma$ 's) in the daytime and in the night-time for \pm 1 night around full moon conditions and ratio sun/moon relative differences $(\Delta$ ratio $)<0.3 \%$ for visible channels (see information included in this figure). Higher $\Delta$ ratio values were obtained for $1020 \mathrm{~nm}$ channel $(0.57 \%)$, attributed to the temperature effect at this spectral range. It implies that a new uncertainty term must be assumed for instruments calibrated by means of the Moon Ratio technique (0.006 for $1020 \mathrm{~nm}$ channel and 0.003 for the rest of channels). Consequently, following Eq. (11), a CE318-T instrument calibrated by means of the Moon Ratio calibration technique has a combined standard estimated uncertainty for visible channels of 0.011-0.013 (0.012-0.014) under full moon (quarter moon) conditions, with the exception of the $440 \mathrm{~nm}$ channel at higher phase angles, with values up to 0.017 . In the $1640 \mathrm{~nm}$ range, we have obtained uncertainties ranging from 0.013 to 0.017 (0.014 to 0.018 ) for full moon (quarter moon), and for the $1020 \mathrm{~nm}$ channel, these values range within $0.014-0.018$ (0.015-0.019) for full moon (quarter moon).

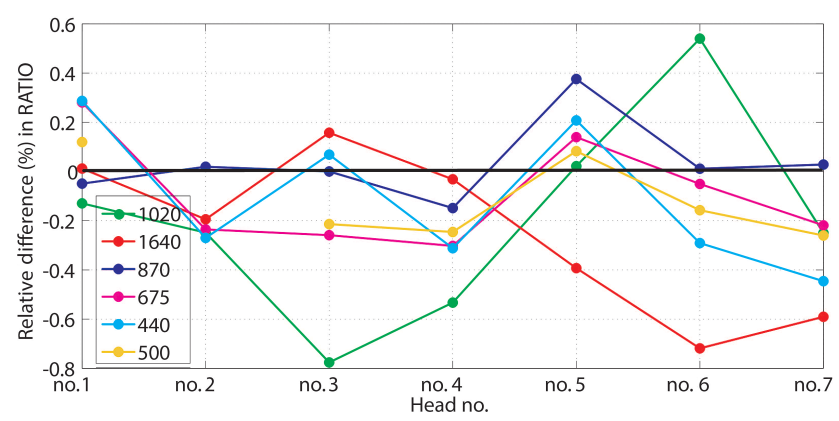

Figure 3. Relative differences between Ratio $_{\text {sun }}$ and Ratiomoon for seven different heads at IZO.

In the case of field instruments calibrated by means of the Sun Ratio technique, we have to take into account the present precision $\leq 1 \%$ in the instrumental resistance gains given by the manufacturer. In this respect we have studied the difference between Ratio sun $_{\text {and }}$ Ratiomoon in near full moon events for seven different heads (all of them installed at IZO during 2014). Our results showed that this relative difference is within the $\pm 1 \%$ stated by the manufacturer as the precision limit, and is wavelength-dependent (Fig. 3). Indeed, this figure shows relative differences $<0.5 \%$ for $\lambda \leq 870 \mathrm{~nm}$ and values up to $0.8 \%$ for near-IR channels. With this information, the additional uncertainty term in those instruments that are Sun Ratio-calibrated can be fixed to values $\leq 0.8 \%$ for near-IR channels and $\leq 0.5 \%$ for channels in the visible range. Therefore, following Eq. (11), the combined nocturnal AOD uncertainty due to $\kappa, I_{0}$ and $V$ uncertainties in a Sun Ratio-calibrated field instrument is expected to be from 0.012 to 0.014 (0.013 to 0.015$)$ for visible wavelength channels at full (quarter) moon conditions with the exception of $440 \mathrm{~nm}$, 
with values up to 0.017 in the case of low moon illumination. For near-IR channels, we obtained values from 0.015 to 0.019 ( 0.016 to 0.020$)$ for the $1640 \mathrm{~nm}$ channel under full (quarter) moon events, and between 0.016 and 0.020 (0.017 and 0.021 ) in the case of the $1020 \mathrm{~nm}$ channel. It assures the validity of the Sun Ratio method for CE318-T calibration as a simple technique with relatively low uncertainties (maximum uncertainties expected to be $\leq 0.021$ ), reducing the complexities of the former Moon Ratio technique considerably.

Finally, in the case of instruments calibrated by means of the Sun-Moon gain factor method, a new contribution in $u(\kappa)$ term must be included in agreement with Eq. (4). Doing so, $u(\kappa)$ depends on the uncertainty associated with the calibration term $u\left(V_{0}\right)(0.002-0.005$ in the case of a reference instrument that is Langley-calibrated), with the contribution of $E_{0}$ solar irradiance model uncertainty and the factor $u(G) / G$ relative to the Sun-Moon gain calculation. We have estimated the $u\left(E_{0}\right) / E_{0}$ contribution in 0.005 , as a conservative value taking into account the inherent uncertainty associated with this type of models (see Gueymard (2003)). In the case of $u(G) / G$ uncertainty, we can consider that the contribution from the integrating sphere is low, since $G$ calculation is based on the ratio of moon and sun measurements, differing as much in 1-2\%o. Therefore, in order to estimate this contribution, we have used the CV of 40 different $G$ values obtained from 10 different moon/sun ratios in four different channels (1640 to $675 \mathrm{~nm}$ ), those having more than 400 counts in the sun (low gain) scenario, finding a $\mathrm{CV}$ value of 0.011 . Considering the instrumental noise term $(u(V))$ and the uncertainty in the ROLO model $\left(u\left(I_{0}\right)\right)$, we have estimated a combined nocturnal AOD uncertainty between 0.016 and 0.017 for all channels, with the exception of the $440 \mathrm{~nm}$ channel, with values up to 0.019 .

A summary of the $u_{\mathrm{AOD}}$ estimation for both reference and field instruments is presented in Table 3.

\subsection{Case study to estimate CE318-T precision}

Precision, defined as the capability of the instrument to perform measurements repeatedly and reliably, can be inferred from the information extracted from the triplets, as we did previously in Sect. 6.1. However, it is also possible to determine the precision in AOD through an analysis of the AOD measurements and their dispersion under very stable AOD conditions. Thus, the standard deviation in AOD ( $\sigma(\mathrm{AOD})$ ) in such conditions provides the information about the instrument's precision. For this purpose, we have selected a case study at IZO of 3 different days and nights between 15 and 18 March 2014, in which AOD conditions were quite stable and moon's illumination was high (full moon in 16 March). In fact, these conditions will be used in Sect. 8 to study the CE318-T performance in more detail. We have coincident daytime AOD information in this time period from the CE318-T master instrument, the CE318-AERONET master instrument and the PFR, as well as night-time AOD information from the same CE318-T master instrument.

Averaged AOD values in the daytime of $0.019,0.013$ and 0.013 were found for PFR, CE318-AERONET and CE318$\mathrm{T}$, respectively, confirming the low aerosol loads in this period. Nighttime averaged AOD was 0.022. The stable AOD conditions were confirmed by means of the analysis of the $\sigma(\mathrm{AOD})$ of each instrument, with daytime values of 0.009 , 0.004 and 0.003 for PFR, CE318-AERONET and CE318-T, respectively, and night-time values of 0.003 . These results confirmed that the CE318-T precision is similar to other reference instruments for both daytime and night-time (under near full moon conditions).

\section{CE318-T intercomparison with reference instruments}

The CE318-T AOD and PWV characterization and assessment was carried out at IZO and Granada. Daytime observations at IZO encompass daytime measurements in 2014 taken on 60 days from 1 March to 30 June; meanwhile at night-time, the study is focused on 32 nights, corresponding to four different moon cycles in 2014: 12-23 March, 7-19 April, 7-13 May and 9-16 June. Nocturnal evaluation performed at Granada station involves 4 nights of collocated measurements CE318-T/star-photometer on 7-8, 9-10, 1112 and 14-15 August 2014.

\subsection{Assessment of the Sun Ratio calibration method}

In order to confirm the suitability of the nocturnal calibration transference using the Ratio Sun technique, we have computed the scatter plot of AOD coincident measurements performed at IZO by the master instrument (direct-suncalibrated and direct-moon-calibrated measurements using the Langley and the Lunar Langley methods according to Sect. 6.1) and the secondary instrument (sun-calibrated using calibration transference and moon-calibrated using both the Sun Ratio and Moon Ratio techniques) (see Fig. 4). The main statistics of the comparison are presented in Table 4 . We observed a good agreement between the AOD retrieved in the daytime from the master instrument and the secondary instrument (mean bias (MB) and root mean square error (RMSE) values $\leq 0.002$ ). For night-time we obtained similar results by calibrating the secondary instrument using the Ratio ${ }_{\text {sun }}$

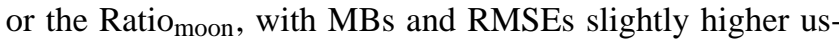
ing daytime ratios, but in all cases within the expected precision for a reference instrument $(\mathrm{MBs}<0.004$ and $\mathrm{RM}$ SEs $<0.008)$.

\subsection{Assessment of the Sun-Moon gain factor calibration method}

We have checked the suitability of the Sun-Moon gain factor calibration technique by comparing the calibration coefficients obtained at night-time by means of the Lunar Lan- 

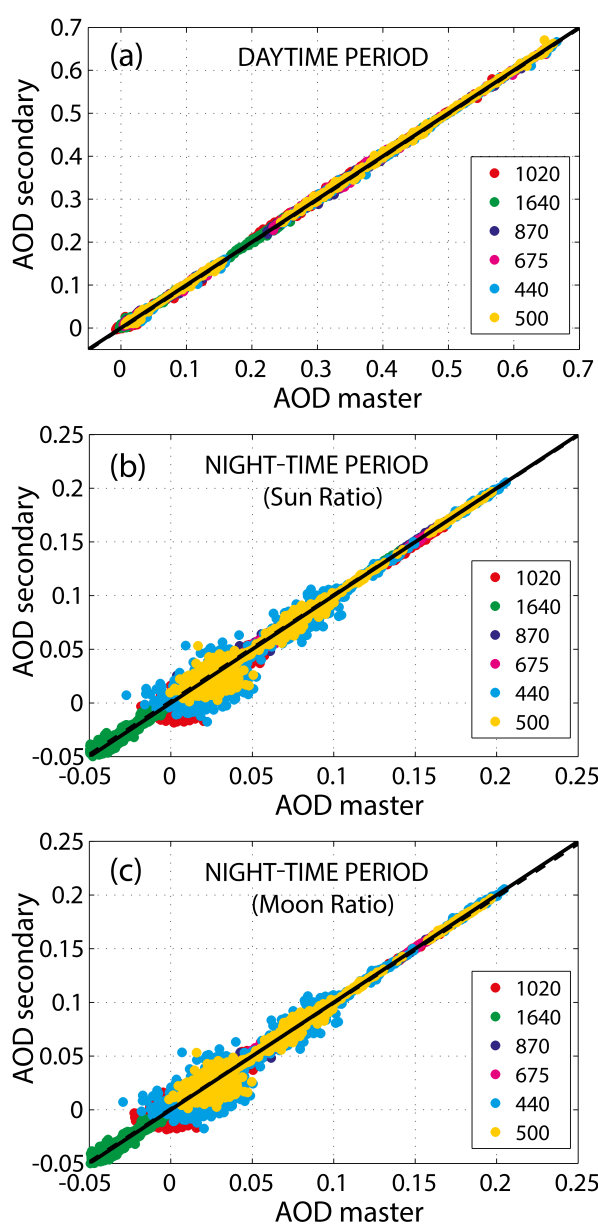

Figure 4. Scatter plot with CE318-T master- vs. secondary-derived AODs for (a) a period of 22 consecutive days and (b) and (c) for a period of 10 consecutive nights in June 2014, with the secondary instrument calibrated using the Sun Ratio and the Moon Ratio techniques, respectively.

gley Method and with this new technique for three different heads calibrated in Izaña between 2014 and 2015. We present the relative differences (in \%) in Table 1 , showing absolute differences of $2.6 \%$ on average including all channels, with larger discrepancies in the 1640 and $1020 \mathrm{~nm}$ channels, 4 and $3.7 \%$ on average, respectively.

In order to quantify the AOD uncertainty involved in this new calibration method we have compared the AOD obtained by the same CE318-T instrument calibrated at Izaña using the Lunar Langley and the Sun-Moon gain factor calibrations techniques in May and June, 2014. This analysis encompasses 6072 coincidences in 17 different days during the two lunar cycles. Table 2 presents the main statistics of this comparison study, showing RMSEs $<0.02$ in $1020-500 \mathrm{~nm}$ wavelength range, within the expected uncertainty presented in Sect. 6 for Sun-Moon gain factor-calibrated field instruments. However, higher discrepancies were found in the case of $1640 \mathrm{~nm}(0.027)$ and $440 \mathrm{~nm}(0.029)$. Further investiga-
Table 1. Relative differences (in \%) in calibration coefficients extracted by means the Sun-Moon gain factor method and the Lunar Langley method for three different heads calibrated at Izaña.

\begin{tabular}{lrrr}
\hline Channel (nm) & Head no. 1 & Head no. 2 & Head no. 3 \\
\hline 1640 & 5.4 & 3.8 & 2.8 \\
1020 & -1.4 & -5.1 & -4.8 \\
870 & 0.7 & -3.7 & -0.7 \\
675 & 0.8 & -3.1 & -1.9 \\
500 & 4.0 & 0.5 & 1.9 \\
440 & 3.5 & 0.7 & 3.3 \\
\hline
\end{tabular}

Table 2. Main statistics of the AOD differences obtained by means the Sun-Moon gain factor method and the Lunar Langley method for one head at Izaña for May and June, 2014. We have included mean bias (MB), standard deviation $(\sigma)$ and root mean square error (RMSE) values.

\begin{tabular}{lrrr}
\hline Channel $(\mathrm{nm})$ & $\mathrm{MB}$ & $\sigma$ & $\mathrm{RMSE}$ \\
\hline 1640 & 0.027 & 0.009 & 0.029 \\
1020 & 0.016 & 0.005 & 0.017 \\
870 & -0.002 & 0.001 & 0.002 \\
675 & 0.005 & 0.002 & 0.006 \\
500 & 0.014 & 0.005 & 0.015 \\
440 & 0.025 & 0.008 & 0.027 \\
\hline
\end{tabular}

tions must be carried out to explain the higher differences found at 1640 and at $440 \mathrm{~nm}$ and to assess the possibility of using these differences to estimate ROLO's residual errors.

\subsection{AOD daytime period intercomparison at IZO}

We have used three independent and collocated measurements at IZO from PFR, PSR and CE318-AERONET to validate the CE318-T master performance during daytime. As WMO (2005) stated, the preferred method of traceability to evaluate the instrument's accuracy is by means of co-location of representative networks' instruments performed at reference wavelengths, trying to ensure a minimum wavelength difference between their channels. Since CE318-T and PFR take measurements at different wavelengths, it is not possible to perform such a comparison at all CE318-T channels. For this reason, we have selected for this intercomparison the channels centred $\sim$ at 870 and $500 \mathrm{~nm}$.

There are other specific limits established by WMO (2005) to ensure successful comparisons, besides the minimum wavelength criteria. These limits are (1) more than 1000 coincident points, (2) minimum of 5 clear sky days, and (3) AOD values within a $0.040-0.200$ range during the comparison period. In this study we have satisfied all the aforementioned limits, as can be seen in the text included in Fig. 5, where the main results of the intercomparison are shown.

In a first stage, we have compared quasi-coincident $( \pm 1 \mathrm{~min})$ AOD measurements in the daytime period ex- 

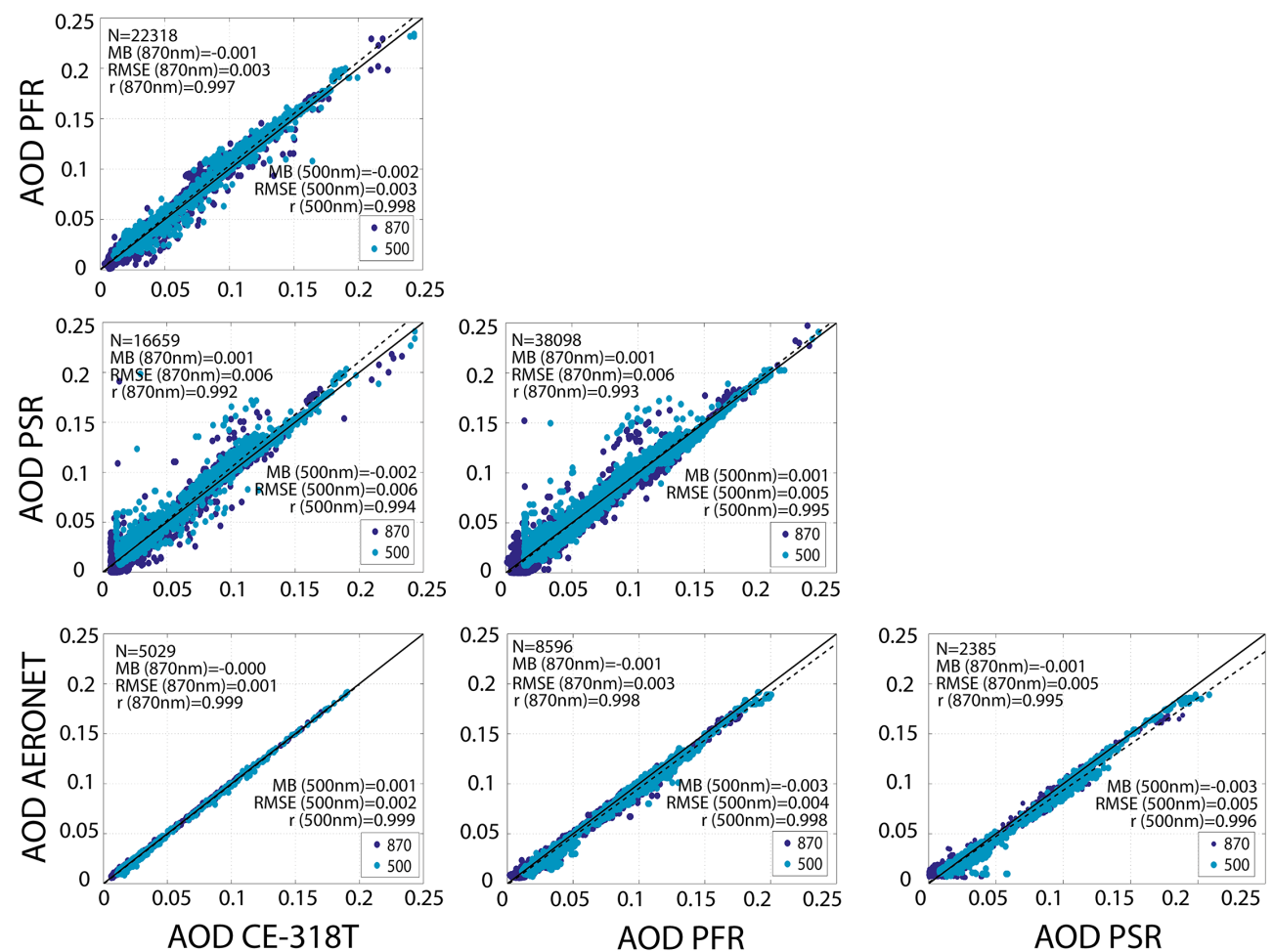

Figure 5. Scatter plots of AOD at $870 \mathrm{~nm}$ (blue) and $500 \mathrm{~nm}$ (cyan) using four different and independent measurements (CE318-T, CE318AERONET, PFR and PSR) during March, April, May and June 2014 at IZO. In each figure, the dotted line represents the linear regression line, and the solid line is the diagonal.

Table 3. Summary for night-time $u_{\mathrm{AOD}}$ estimated values for visible (VIS) and near-IR (nIR) channels considering the four different calibration techniques: Lunar Langley method (LLM), Ratio Moon (RM), Ratio Sun (RS) and Sun-Moon gain factor (SMG) methods. These results are presented for different moon illumination conditions: full moon (FM) and quarter moon (QM).

\begin{tabular}{rrrrr}
\hline & & VIS & $440 \mathrm{~nm}$ & $\mathrm{nIR}$ \\
\hline \multirow{2}{*}{ LLM } & FM & $\pm 0.011-0.013$ & $\pm 0.011-0.013$ & $\pm 0.012-0.017$ \\
& QM & $\pm 0.012-0.014$ & $\pm 0.012-0.016$ & $\pm 0.013-0.018$ \\
\hline \multirow{2}{*}{ RM } & FM & $\pm 0.011-0.013$ & $\pm 0.011-0.013$ & $\pm 0.013-0.017$ \\
& QM & $\pm 0.012-0.014$ & $\pm 0.012-0.017$ & $\pm 0.014-0.018$ \\
\hline \multirow{2}{*}{ RS } & FM & $\pm 0.012-0.014$ & $\pm 0.012-0.014$ & $\pm 0.015-0.020$ \\
& QM & $\pm 0.013-0.015$ & $\pm 0.013-0.017$ & $\pm 0.016-0.021$ \\
\hline \multirow{2}{*}{ SMG } & FM & \pm 0.016 & \pm 0.016 & \pm 0.016 \\
& QM & \pm 0.017 & $\pm 0.017-0.019$ & \pm 0.017 \\
\hline
\end{tabular}

tracted from CE318-T and CE318-AERONET in the 60-day period from March to June 2014 (Fig. 5). MB $\leq 0.001$ and RMSE $\leq 0.002$ were obtained, in addition to high regression coefficients $>0.99$. These values are consistent with the AOD uncertainty associated with high-mountain-calibrated reference instruments presented by Eck et al. (1999).
A subsequent intercomparison study using CE318-T and PFR, as well as between CE318-T and PSR in the same period, encompasses coincident daylight measurements at IZO in a temporal window of $\pm 1 \mathrm{~min}$. We can see a good agreement between AOD extracted from CE318-T and PFR/PSR instruments $(r>0.99)$ and MBs and RMSEs below 0.003 for PFR, and MBs and RMSEs below 0.006 for PSR. Skill scores obtained for CE318-T and PFR are similar to the values obtained by Nyeki et al. (2013) in a 5-month comparison at IZO in 2009 and better than those found by Kazadzis et al. (2014) in Athens, Greece, using ground instruments. We have also compared collocated PSR/PFR, AERONET/PFR and AERONET/PSR, finding similar results to those obtained in the two last comparisons (MBs $\leq 0.003$ and RMSEs $\leq 0.006$ for all comparisons in both channels).

WMO (2005) also stated that an acceptable traceability exists only if differences in AOD between reference instrument lie within acceptance limits, which are defined for finite field-of-view instruments in function of air mass $\left(m_{\mathrm{a}}\right)$. They defined the expanded uncertainty limits at a $95 \%$ confidence level as $U_{95}= \pm\left(0.005+0.010 / m_{\mathrm{a}}\right)$, matching the level of 2 standard deviations for a Gaussian distribution. Therefore, this type of criterion assumes that our error distribution follows a normal distribution. All the $U_{95}$ values for all instruments in this comparison are within the specified limits (Fig. 6). $U_{95}$ levels are similar to the values obtained 
Table 4. Statistics of the master vs. secondary AOD comparison: mean bias (MB), root mean square error (RMSE) and Pearson correlation coefficient $(r)$.

\begin{tabular}{lrrrrrr}
\hline \multicolumn{6}{l}{ Daylight $(N=5566)$} \\
\hline Channel $(\mathrm{nm})$ & 1020 & 1640 & 870 & 675 & 440 & 500 \\
MB & 0.001 & 0.002 & 0.001 & 0.001 & 0.001 & 0.002 \\
RMSE & 0.002 & 0.002 & 0.002 & 0.002 & 0.000 & 0.002 \\
$r$ & 0.999 & 0.999 & 0.999 & 0.999 & 0.999 & 0.999 \\
\hline \multicolumn{7}{l}{ Night-time - Sun Ratio $(N=2319)$} \\
\hline MB & -0.004 & 0.001 & -0.001 & -0.002 & -0.002 & -0.001 \\
RMSE & 0.006 & 0.003 & 0.003 & 0.004 & 0.008 & 0.005 \\
$r$ & 0.996 & 0.999 & 0.998 & 0.998 & 0.992 & 0.996 \\
\hline Night-time - Moon Ratio $(N=2319)$ & & & & \\
\hline MB & -40.001 & 0.000 & -0.001 & -0.000 & -0.001 & -0.000 \\
RMSE & 0.005 & 0.002 & 0.003 & 0.003 & 0.007 & 0.005 \\
$r$ & 0.996 & 0.999 & 0.998 & 0.998 & 0.992 & 0.996 \\
\hline
\end{tabular}
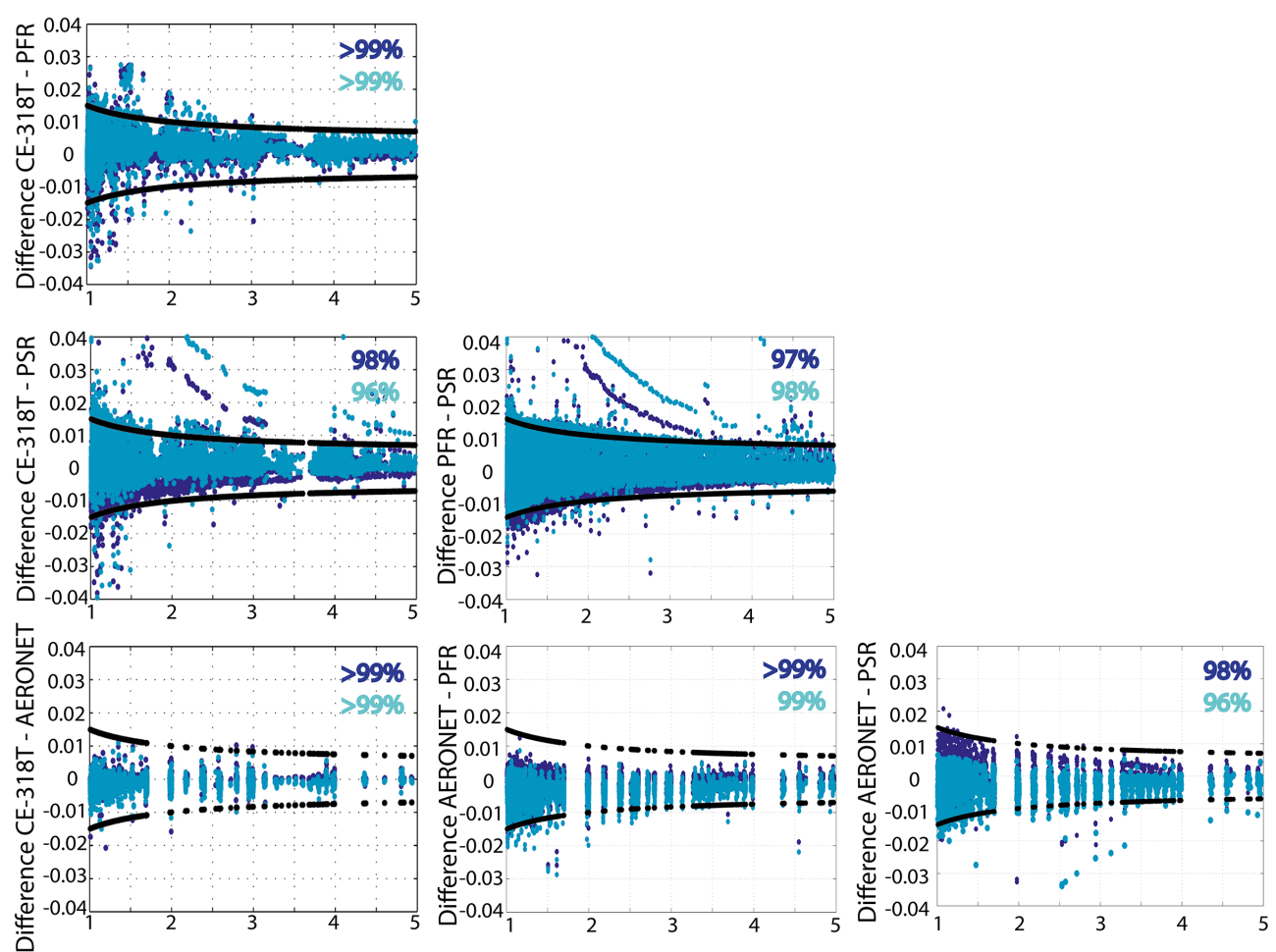

Air mass

Figure 6. AOD differences vs. air mass for the channel centred at $870 \mathrm{~nm}$ (blue) and $500 \mathrm{~nm}$ (cyan). The solid line represents the $U 95$ uncertainty limit. In each figure panel, the percentage of points within the $U 95$ limits is included.

by Nyeki et al. (2013) when comparing the standard CE318AERONET with PFR at IZO. Values for $870 \mathrm{~nm}$ channels are also in agreement with those results found by Kazadzis et al. (2014) for AERONET-PFR comparison at Athens, but our results for the $500 \mathrm{~nm}$ channel are considerably better.

Consequently, we have obtained similar AOD differences in the daytime between CE318-T and reference instruments, as the current CE318-AERONET master instrument and the PFR. As a result, we can anticipate a precision of the new CE318-T in the daytime similar to the other reference instruments, which is in agreement with the expected daytime accuracies presented in Sect. 6 . 


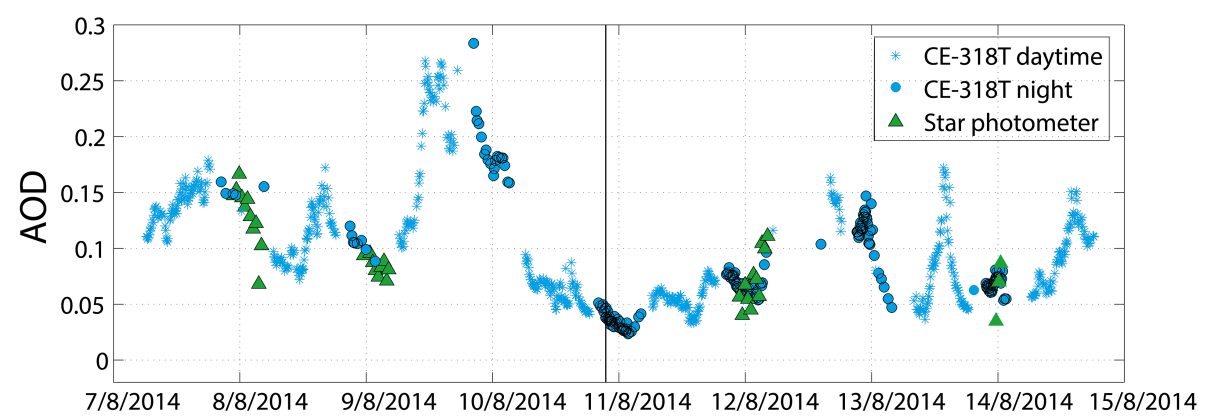

Figure 7. AOD at the $500 \mathrm{~nm}$ channel from CE318-T in the daytime and night-time (in blue), and from the star photometer (in green) at Granada in 8 consecutive days in August 2014. Vertical line represents the full moon phase.

\subsection{AOD nocturnal intercomparison at Granada}

Coincident measurements of the CE318-T secondary instrument (Sun Ratio-calibrated) and the star photometer in a temporal window of \pm 15 min were performed at Granada during 4 nights in August 2014 (7-8, 8-9, 11-12 and 1415). During this period, stellar information in 880,500 and $440 \mathrm{~nm}$ channels, close to CE318-T wavelengths, were extracted. Main statistics of the comparison are presented in Table 5, showing high regression coefficients for the three channels and reduced MBs and RMSEs in the case of longer wavelength channels $(\leq 0.001$ for $870 \mathrm{~nm}$ and $\leq 0.013$ for $500 \mathrm{~nm}$ ). Higher discrepancies were found in the case of the $440 \mathrm{~nm}$ channel $(\mathrm{MB}=-0.033$ and RMSE $=0.018)$. The sequence of AOD measured at $500 \mathrm{~nm}$ by CE318-T in the daytime and night-time are displayed in Fig. 7, as well as star photometer night-time AODs. The scatter plot of AOD extracted from these two instruments at 870,500 and $440 \mathrm{~nm}$ channels is shown in Fig. 8. There is a good agreement between both instruments in the case of the 870 and $500 \mathrm{~nm}$ channels, with discrepancies lower than the expected accuracies for the star photometer published by Pérez-Ramírez et al. (2011) and also lower than the errors presented in Sect. 6 for field instruments. On the contrary, the differences found in the case of the $440 \mathrm{~nm}$ channel are higher than those expected for star photometry and slightly higher than the maximum uncertainty values for CE318-T field instruments in visible channels theoretically estimated using Eq. $(11)(\leq 0.017$ for secondary Sun Ratio-calibrated instruments). This might be attributed to a calibration problem in the star photometer in this channel.

\subsection{AOD day/night transition coherence test}

The daytime and night-time AOD evolution extracted at IZO from the CE318-AERONET master instrument and the CE318-T master instrument for a sequence of four moon cycles in March, April, May and June 2014 (60 days and 32 nights) is shown in Fig. 9. The moon's fraction of illumination (FI) is also depicted in each AOD figure to show the accuracy dependence of CE318-T nocturnal retrievals on
Table 5. Statistics of the CE318-T and star photometer AOD comparison during August 2014: mean bias (MB), root mean square error (RMSE), Pearson correlation coefficient $(r)$ and number of coincidences $(N)$.

\begin{tabular}{lrrr}
\hline Channel $(\mathrm{nm})$ & 870 & 500 & 440 \\
\hline MB & -0.001 & 0.013 & -0.033 \\
RMSE & 0.003 & 0.009 & 0.018 \\
$r$ & 0.946 & 0.937 & 0.911 \\
$N$ & 15 & 15 & 14 \\
\hline
\end{tabular}

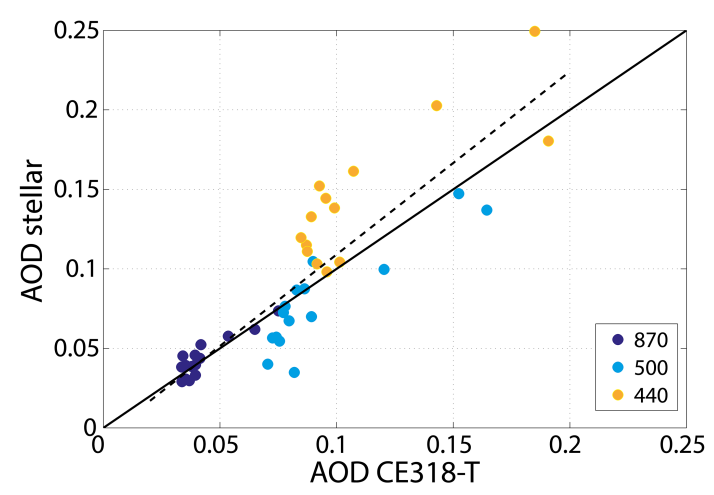

Figure 8. Scatter plot CE318-T AOD vs. stellar AOD at Granada for 4 nights in August 2014. The dotted line represents the linear regression line, and the solid line is the $1: 1$ line.

the lunar phase. An artificial AOD cycle with the moon's zenith angle is readily observed in Fig. 9 for the case of low AOD events. The result is a curvature in AOD with maximum absolute values when the moon zenith angle is minimum. This cycle is more important in the case of the $1640 \mathrm{~nm}$ channel. The quantitative analysis of AOD differences between the daytime and night-time period with respect to FI is shown in Tables 6 and 7, in which we have compared nocturnal (CE318-T) and daytime (CE318-AERONET) data corresponding to the consecutive $1 \mathrm{~h}$ time period during moonsetsunrise (MS-SR, 23 events) and sunset-moonrise (SS-MR, 20 events) for different illumination conditions, assuming sta- 

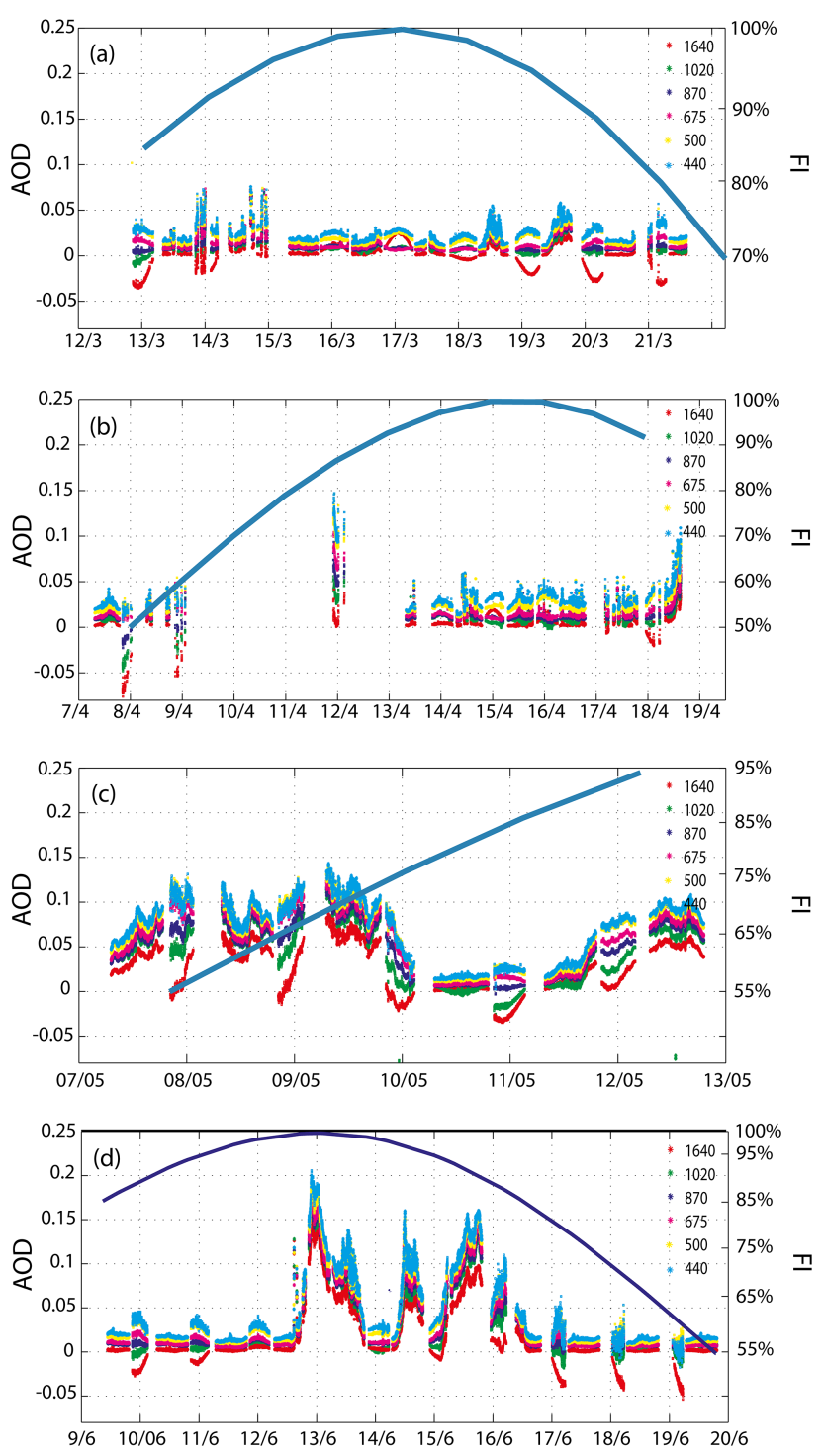

Figure 9. Diurnal CE318-AERONET/CE318-T AOD evolution during (a) March, (b) April, (c) May and (d) June 2014 at IZO. The blue line and right $y$ axis correspond to the evolution in this period of the moon's factor of illumination (FI).

ble AOD conditions. In this respect, no significant changes in aerosol loads were observed during this period, with the exception of the variations in AOD observed on 10-11 May and on 12-13, 14-15 and 15-16 June. These data have not been included in the analysis. MS-SR events are representative of conditions before full moon, while SS-MR events are typically observed after full moon. These tables show that, in general for MS-SR events, MBs for channels with shorter wavelengths $(\lambda \leq 870 \mathrm{~nm})$ and for any illumination condition are $\leq 0.015$, slightly higher than the values reported by Eck et al. (1999) and Schmid et al. (1999) for reference instruments but within the expected uncertainties calculated in Sect. 6. Somewhat higher differences appeared in SS-MR events, when MBs and RMSEs $\leq 0.018$ (0.022 for the $440 \mathrm{~nm}$ channel) are retrieved, with the exception found at FI between 70 and $80 \%$, when we obtained an MB of 0.024 for the $870 \mathrm{~nm}$ channel, while an MB value of -0.001 is obtained for similar illumination conditions in the case of the MS-SR period. In the case of longer wavelength channels $(1020$ and $1640 \mathrm{~nm})$ we have found significant discrepancies for low illumination conditions (MBs $>0.06$ ), especially in the $1640 \mathrm{~nm}$ channel, with higher differences after full moon conditions. In these channels MBs $<0.02$ can only be found under $\mathrm{FI} \geq 90 \%$. Generally, the lower the RMSE values, the higher the moon's illumination.

This information shows that the values estimated by Eq. (11) and presented in Sect. 6 for CE318-T nocturnal AOD uncertainty match reasonably well the mean differences obtained in this coherence test for visible channels under all illumination conditions (up to 0.016 for reference instruments) and for near-infrared channels (up to 0.018 for reference instruments) only for high FI conditions (>90\%). The artificial nocturnal cycle on AOD is observed for any wavelength, with a minor impact at $\lambda<1020 \mathrm{~nm}$, the channel centred at $1640 \mathrm{~nm}$ being the most affected channel. The reason for this nocturnal cycle is unclear, and further investigations must be developed to clarify it, although it possibly reflects a problem in the instrument calibration, in the nighttime AOD calculation and/or in the lunar irradiance model.

\subsection{Precipitable water vapour intercomparison}

We have compared \pm 15 min quasi-coincident daytime PWV data from the CE318-T master instrument with CE318AERONET data (Fig. 10a) and GNSS precise orbits for daytime and night-time at IZO (Fig. 10b). In the same time period as in previous sections, PWV measured with GNSS was 0.37 and $0.32 \mathrm{~cm}$ during daytime and night-time, respectively, and $0.29 \mathrm{~cm}$ for both daytime and night-time in the case of CE318-T. We have used the same criteria as in the previous AOD comparison to quantitatively determine the nocturnal discrepancies as a function of FI. This information is presented in Table 8. Daytime CE318-T PWV matches AERONET data reasonably well, with discrepancies and RMSEs $\sim 0.02 \mathrm{~cm}$ and high regression coefficient $(r=0.99)$. The daytime comparison of CE318-T against GNSS data (Fig. 10b) also showed a good correlation between data $(r=0.97)$ but higher MBs $(-0.09 \mathrm{~cm})$, showing the existence of a slight negative bias between instruments, and slightly higher RMSEs $(0.05 \mathrm{~cm})$. In the case of nocturnal data, we observe a similar negative bias to those obtained in the daytime. MB values remain lower than daytime values for any FI. Regarding RMSE, only near full moon events have similar RMSEs than daytime period. We obtained RMSE values ranging from $0.09 \mathrm{~cm}$ for $\mathrm{FI}<60 \%$ to $0.05 \mathrm{~cm}$ under near full moon events. Daytime as well as nocturnal measurements are within the expected precision of CE318-AERONET and GNSS under such dry conditions, 
Table 6. MB and RMSE values for AOD differences between CE318-AERONET daytime and CE318-T night-time data during sunsetmoonrise (SS-MR, defined as the last $1 \mathrm{~h}$ of daytime data vs. the first $1 \mathrm{~h}$ of nocturnal data) as a function of the average moon's fraction of illumination $(\mathrm{FI})$.

\begin{tabular}{lllrrrrrr}
\hline & & \multicolumn{7}{c}{ SS-MR } \\
& \multirow{2}{*}{ No. cases } & & 1020 & 1640 & 870 & 675 & 500 & 440 \\
\hline \multirow{2}{*}{$60 \% \geq$ FI $>50 \%$} & \multirow{2}{*}{2} & MB & 0.035 & 0.061 & 0.012 & -0.015 & -0.008 & -0.019 \\
& & RMSE & 0.037 & 0.062 & 0.017 & 0.018 & 0.014 & 0.022 \\
\hline \multirow{2}{*}{$70 \% \geq$ FI $>60 \%$} & \multirow{2}{*}{2} & MB & 0.029 & 0.051 & 0.008 & -0.014 & -0.007 & -0.015 \\
& & RMSE & 0.029 & 0.051 & 0.009 & 0.014 & 0.008 & 0.016 \\
\hline \multirow{2}{*}{$80 \% \geq$ FI $>70 \%$} & \multirow{2}{*}{1} & MB & 0.048 & 0.056 & 0.024 & 0.008 & 0.016 & 0.006 \\
& & RMSE & - & - & - & - & - & - \\
\hline \multirow{2}{*}{$90 \% \geq$ FI $>80 \%$} & \multirow{2}{*}{4} & MB & 0.016 & 0.027 & 0.001 & -0.010 & -0.012 & -0.016 \\
& & RMSE & 0.018 & 0.027 & 0.003 & 0.011 & 0.013 & 0.016 \\
\hline \multirow{2}{*}{$95 \% \geq$ FI $>90 \%$} & \multirow{2}{*}{3} & MB & 0.001 & 0.010 & -0.004 & -0.010 & -0.016 & -0.016 \\
& & RMSE & 0.003 & 0.010 & 0.006 & 0.012 & 0.017 & 0.017 \\
\hline \multirow{2}{*}{$\mathrm{FI} \geq 95 \%$} & \multirow{2}{*}{8} & MB & 0.015 & 0.009 & 0.014 & 0.013 & 0.010 & 0.012 \\
& & RMSE & 0.008 & 0.006 & 0.008 & 0.008 & 0.008 & 0.008 \\
\hline
\end{tabular}

Table 7. MB and RMSE values for AOD differences between CE318-AERONET daytime and CE318-T night-time data during moonsetsunrise (MS-SR, as the first $1 \mathrm{~h}$ of daytime data vs. the last $1 \mathrm{~h}$ of nocturnal data) as a function of the average moon's fraction of illumination (FI).

\begin{tabular}{lllrrrrrr}
\hline & \multicolumn{7}{c}{ MS-SR } \\
& \multirow{2}{*}{ No. cases } & & 1020 & 1640 & 870 & 675 & 500 & 440 \\
\hline \multirow{2}{*}{$50 \% \geq$ FI $>60 \%$} & \multirow{2}{*}{1} & MB & 0.012 & 0.046 & 0.003 & -0.009 & -0.008 & -0.006 \\
& & RMSE & - & - & - & - & - & - \\
\hline \multirow{2}{*}{$60 \% \geq$ FI $>70 \%$} & \multirow{2}{*}{1} & MB & 0.007 & 0.039 & -0.002 & -0.014 & -0.005 & -0.015 \\
& & RMSE & - & - & - & - & - & - \\
\hline \multirow{2}{*}{$80 \% \geq$ FI $>70 \%$} & \multirow{2}{*}{2} & MB & 0.007 & 0.034 & -0.001 & -0.012 & -0.012 & -0.017 \\
& & RMSE & 0.010 & 0.034 & 0.003 & 0.012 & 0.013 & 0.017 \\
\hline \multirow{2}{*}{$90 \% \geq$ FI $>80 \%$} & \multirow{2}{*}{4} & MB & 0.012 & 0.023 & 0.009 & 0.002 & -0.001 & -0.001 \\
& & RMSE & 0.002 & 0.012 & 0.001 & 0.006 & 0.009 & 0.009 \\
\hline \multirow{2}{*}{$95 \% \geq$ FI $>90 \%$} & \multirow{2}{*}{4} & MB & 0.011 & 0.016 & 0.007 & -0.002 & -0.002 & -0.001 \\
& & RMSE & 0.015 & 0.018 & 0.011 & 0.009 & 0.011 & 0.010 \\
\hline \multirow{2}{*}{ FI $\geq 95 \%$} & \multirow{2}{*}{11} & MB & -0.001 & -0.003 & -0.002 & -0.004 & -0.009 & -0.006 \\
& & RMSE & 0.002 & 0.004 & 0.002 & 0.004 & 0.008 & 0.006 \\
\hline
\end{tabular}

as reported by Schneider et al. (2010). These authors found a CE318-AERONET expected precision ranging from 7 to $25 \%$ from dry to humid conditions, and the GNSS precision was within $10-20 \%$ in the case of PWV $\leq 0.35 \mathrm{~cm}$, as in our case. These values also agree with the values found by Barreto et al. (2013b) in the comparison between CE318-U and GNSS PWV data.

PWV comparison at Granada allows us to extend the last evaluation procedure to wetter conditions, including GNSS data for 9 different days and 5 different nights in August
2014 (Fig. 10c), with PWV values up to $3 \mathrm{~cm}$. The comparison criteria are also $\pm 15 \mathrm{~min}$. Since this information has been obtained using the secondary CE318-T instrument, it has served us as a new evaluation of the secondary's calibration. PWV averaged during this period is $1.70 \mathrm{~cm}$ for GNSS and $1.55 \mathrm{~cm}$ for CE318-T for daytime, and 1.90 and $1.98 \mathrm{~cm}$, respectively, for night-time. We have found $\mathrm{MBs}$ of -0.15 and $0.09 \mathrm{~cm}$, for daytime and night-time, respectively, both within the 7-25\% precision expected for CE318AERONET and 10-20\% precision for GNSS. RMSEs of 
Table 8. Main statistics of the PWV comparison (in $\mathrm{cm}$ ) extracted from CE318-T, CE318-AERONET and GNSS for daytime data, and from CE318-T and GNSS for nocturnal data. In the case of nighttime information a comparison in function of the moon's fraction of illumination (FI, in \%) is also included.

\begin{tabular}{lrrrr}
\hline & \multicolumn{5}{c}{ Day } \\
\hline Instruments & MB & RMSE & $r$ & $N$ \\
\hline CE318-T/CE318-AERONET & -0.02 & 0.02 & 0.99 & 1935 \\
CE318-T/GNSS & -0.09 & 0.05 & 0.97 & 461 \\
\hline \multicolumn{5}{c}{ Night } \\
& MB & RMSE & $r$ & $N$ \\
\hline CE318-T/GNSS & -0.08 & 0.09 & 0.99 & 10 \\
\hline $60 \% \geq$ FI $>50 \%$ & -0.07 & 0.08 & 0.99 & 10 \\
$70 \% \geq$ FI $>60 \%$ & -0.01 & 0.02 & 0.98 & 10 \\
$80 \% \geq$ FI $>70 \%$ & -0.03 & 0.07 & 0.99 & 43 \\
$90 \% \geq$ FI $>80 \%$ & -0.03 & 0.06 & 0.98 & 41 \\
$95 \% \geq$ FI $>90 \%$ & -0.02 & 0.05 & 0.99 & 93 \\
$100 \% \geq$ FI $>95 \%$ & & & & 207 \\
\hline Total & &
\end{tabular}

0.14 and $0.07 \mathrm{~cm}$ and regression coefficients of 0.83 and 0.85 were obtained, respectively.

\section{Demonstration case study}

The purpose of these case studies is to assess in more detail the performance of the CE318-T master instrument under both very clean free-troposphere and dusty conditions, with a quick transition between the two scenarios. This case analysis also provides an opportunity to explore new potential scientific applications of CE318-T since it can measure diurnal changes of aerosols and water vapour (during daytime and night-time periods) with high temporal resolution, helping to improve our understanding of short-term atmospheric processes.

\subsection{IZO, June 2014}

During the period 10-18 June 2014, three dust-laden intrusions of the SAL, followed by clean background freetroposphere conditions, were recorded at IZO with the MPL and the CE318-T (Fig. 11). The coherence between the backscatter signal (Fig. 11a) and the AOD evolution (Fig. 11b) can be seen in this figure. The onset of two of the three dust intrusions are clearly detected in both figures in the late hours of 12 June and also in the initial hours of 15 June. The intrusion detected by CE318-T on 14 June was not recorded by MPL because of the presence of thick clouds observed at altitudes below IZO, which completely attenuated the lidar signal. Regarding the AE evolution (Fig. 11c), we observe a good agreement between daytime and nighttime measurements during SAL conditions, as is the case of
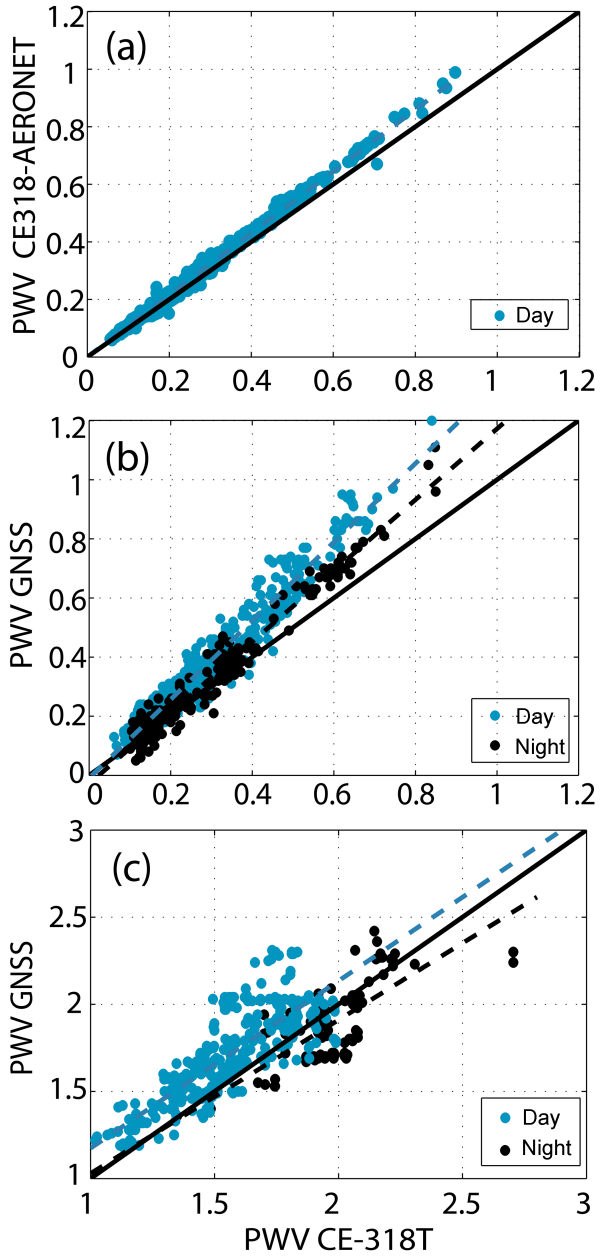

Figure 10. Scatter plot with daytime (in blue) CE318-T master PWV (in cm) vs. (a) CE318-AERONET, (b) daytime and night-time master (black) CE318-T PWVs (in cm) vs. GNSS, and (c) daytime and night-time PWV comparison performed at Granada station using the secondary CE318-T and GNSS ultra-rapid orbits. The dotted line represents the linear regression line and the solid line the $1: 1$ line in all figures.

13 June. However, we observe the presence of a diurnal cycle in $\mathrm{AE}$ under free-troposphere conditions, with predominantly higher values of $\mathrm{AE}$ at night-time. The first feature is a consequence of the homogeneity of SAL conditions in terms of aerosol properties (Smirnov et al., 1998), while the second feature is attributable to the strengthening of freetroposphere conditions driven by the katabatic regime during night-time, causing an increase in $\mathrm{AE}$ associated with pristine near aerosol-free Rayleigh conditions. This figure also shows the expected higher dispersion in AE as the moon's illumination drops. Other assessments can be done from the PWV records (Fig. 11d) within the three SAL events. The expected increase in PWV as a result of the dust intrusions is observed. Saharan air masses are characterized by relatively low and stable humidity levels, but are higher than 


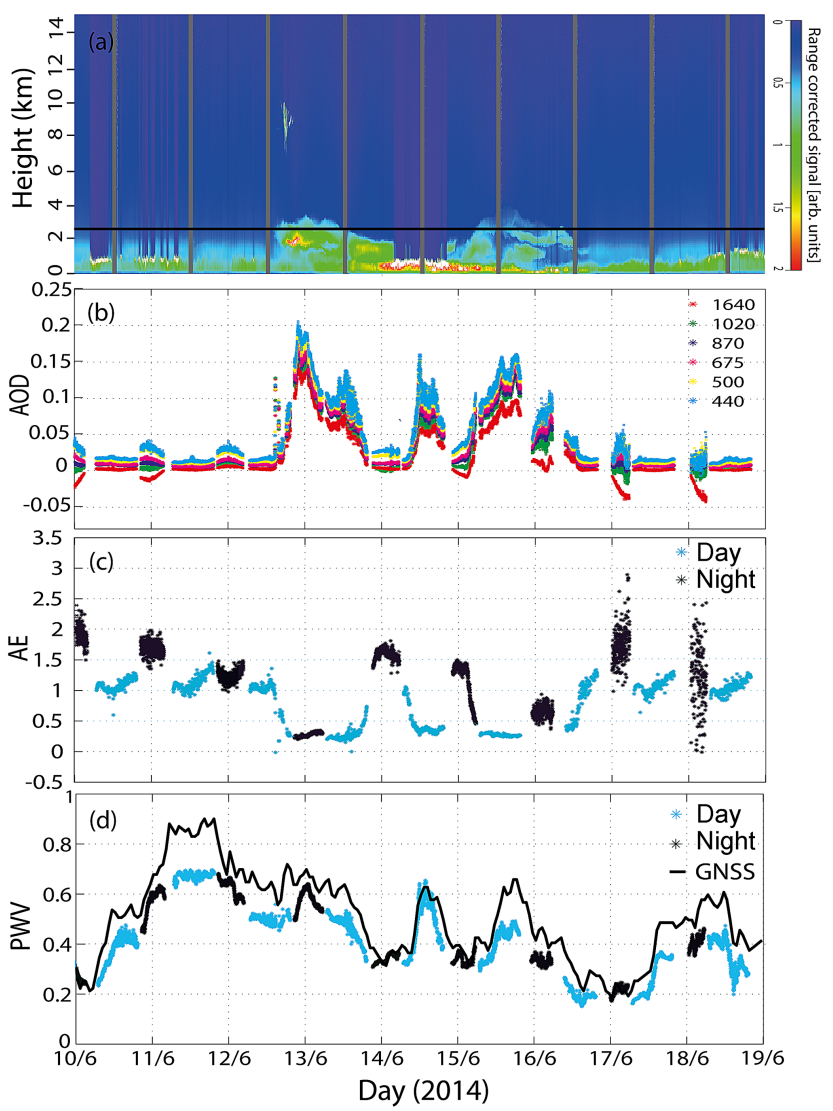

Figure 11. Case study at IZO in June, 2014, including information for (a) MPL-corrected backscatter cross section obtained from Santa Cruz de Tenerife station (60 ma.s.1.). The black horizontal line represents the altitude of IZO station. Grey vertical lines represent the absence of measurements. The evolution of CE318-T AOD, AE and PWV from 10 to 19 June 2014 is shown in (b), (c) and (d). PWV values from GNSS precise orbits are plotted with a black solid line.

those normally present under clean free-troposphere conditions, driven by a subsidence regime. This is the case of 13 June at night and 14 June at noon, perfectly matching the dust intrusions. These features were similarly detected by GNSS.

\subsection{IZO, March 2014}

This is an example of free-troposphere conditions affecting IZO during several days (Fig. 12). In this case, from 16 to 21 March, there were pristine conditions, with AOD below 0.05 (Fig. 12b). Even under these background conditions, data from the CE318-T reveal valuable information about atmospheric processes. A diurnal cycle in AE is still present, where the AE typically reaches its minimum approximately in the early hours of the morning, between 04:00 and 06:00 UTC, while the maximum is reached in the second half of the day (Fig. 12c). Regarding PWV, we have found that under these free-troposphere conditions, both CE318-
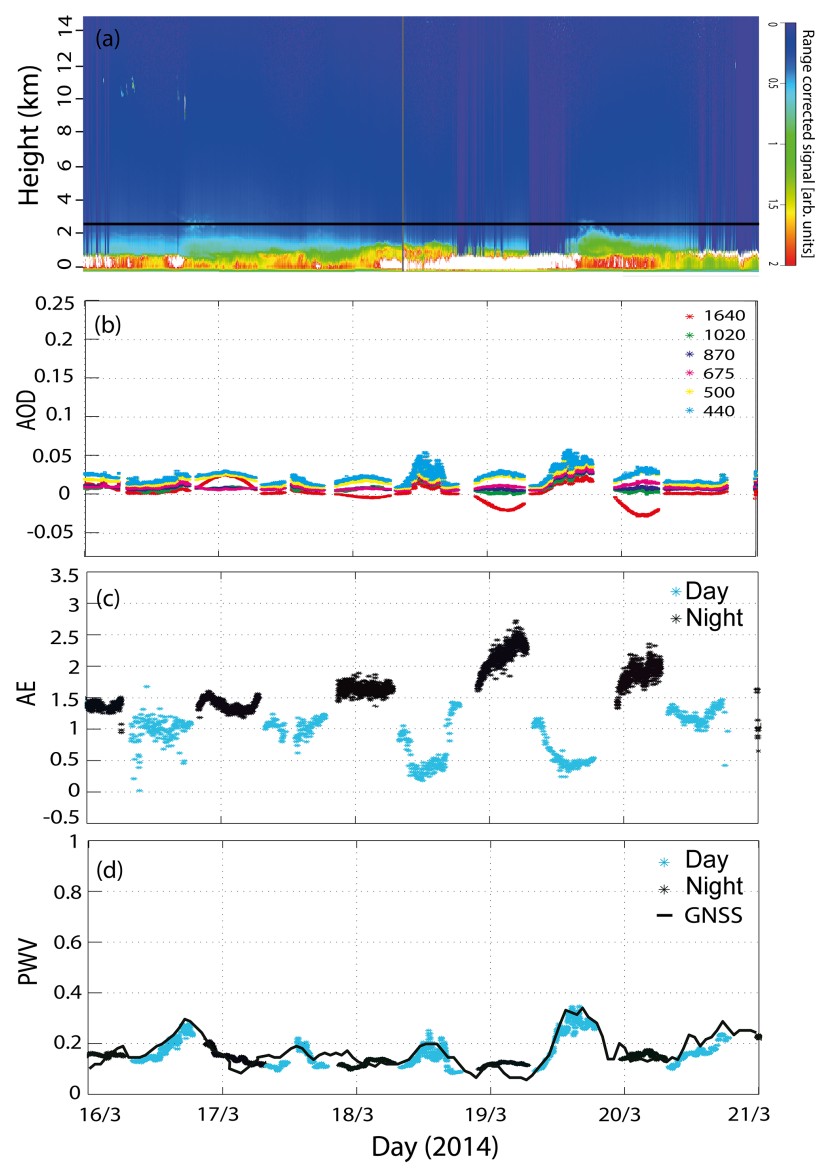

Figure 12. Case study at IZO in March 2014, including information for (a) MPL-corrected backscatter cross section obtained from Santa Cruz de Tenerife station (60 ma.s.l.). The black horizontal line represents the altitude of IZO station. Grey vertical lines represent the absence of measurements. The evolution of CE318-T AOD, AE and PWV from 16 to 21 March 2014 is shown in (b), (c) and (d). PWV values from GNSS precise orbits are plotted with a black solid line.

$\mathrm{T}$ and GNSS are capable of detecting a diurnal variation in atmospheric humidity with a maximum during daytime. The diurnal cycle is still an issue that is currently being investigated and some explanations have been hypothesized. Some authors have analysed GNSS data partially and attribute the PWV diurnal variation to an artifact related with diurnal changes of the mean temperature of the layer (Ortiz de Galisteo et al., 2010). Other authors explain these variations by diurnal variations of temperature and winds (Suparta et al., 2009), water vapour transport by turbulent mixing with the development of the boundary layer in the afternoon ( $\mathrm{Wu}$ et al., 2003) or by evaporation and condensation within the air mass and wet or dry advection by local winds (Ortiz de Galisteo et al., 2010). In our case, we attribute the PWV diurnal variation to diurnal evolution of the marine boundary layer which introduces small amounts of water vapour in the 
free troposphere near noon, reinforced by the sharp topography of the island and the consequent valley-land breeze system established on a daily basis. This is confirmed by the diurnal evolution of the boundary layer (BL) top altitude (not shown here) which can vary over $1000 \mathrm{~m}$ between noon and midnight. The BL top height has been obtained from radiosonde data at 00:00 and 12:00 UTC from the WMO GUAN station no. 60018 (Güímar, Tenerife), $13 \mathrm{~km}$ distance from IZO. The criteria used to account for the BL top altitude are $\Delta \theta / \Delta z \geq 0.0025 \mathrm{~km}^{-1}$ and $\theta_{\text {top }} / \theta_{\text {base }} \geq 1 \mathrm{~K}$, where $\Delta \theta / \Delta z$ is the potential temperature lapse rate, and $\theta_{\text {top }}$ and $\theta_{\text {base }}$ correspond to the top and base of the layer, respectively (Cuesta et al., 2008; Guirado et al., 2014).

With this information we can verify that CE318-T has sufficient accuracy to capture the diurnal cycle of aerosols and PWV associated with local and short-term atmospheric variations. These examples show us the high sensitivity of the new CE318-T photometer, capable of detecting small-scale atmospheric processes which will permit new studies which were impossible to tackle before with standard sun photometers.

\section{Summary and conclusions}

In this paper we have described the new photometer CE318$\mathrm{T}$, designed to perform a complete cycle of diurnal photometric measurements during both daytime and night-time. New improvements permit this new photometer to extend photometric information at night-time using the moon as a light source. Our comparative results of the instrument's triplets measured by two master instruments (CE318-T and CE318-AERONET) installed in IZO showed a better precision of the CE318-T as a result of its improved tracking system. We have also presented four different approaches for CE318-T calibration. The methodology for an absolute calibration involves the Langley and the Lunar Langley techniques, for day and night measurements, respectively; meanwhile the nocturnal calibration transference from a master instrument can be performed using the Moon Ratio method and the new Sun Ratio technique. The latter technique requires a reference moon-calibrated instrument and daytime measurements. We have also presented a fourth calibration technique, the Sun-Moon gain factor technique, which only requires a reference sun-calibrated instrument and daytime measurements and is not dependent on any lunar irradiance model. The last two techniques allow the reduction of the complexities inherent to nocturnal calibration due to the low signal captured at night-time and the short period within a moon cycle to perform the instrument calibration. We assessed the Sun Ratio technique by an AOD intercomparison of a CE318-T master instrument Langley-calibrated with a secondary instrument calibrated using this method. A good agreement between both AOD retrievals was found, with $\mathrm{MB}<0.002$ for daytime and $<0.004$ for night-time. The Sun-Moon gain factor technique was assessed by compar- ing the AOD obtained by the same instrument that is $\mathrm{Lu}$ nar Langley-calibrated and Sun-Moon gain factor-calibrated, obtaining discrepancies $<0.02$ for $1020-500 \mathrm{~nm}$ wavelength range, and higher differences for $1640 \mathrm{~nm}$ and $440 \mathrm{~nm}$ (up to 0.029 ). It is also important to highlight the advantages that the Sun-Moon gain factor calibration method offers in terms of accuracy and simplicity, since it is not affected by the ROLO's uncertainty and requires only daytime collocated measurements from a sun-calibrated reference instrument. These advantages would imply that a Sun-Moon gain factor CE318-T calibrated instrument may be used to measure the moon irradiance at surface level, which could be useful to infer extraterrestrial moon irradiance in the case of the atmospheric turbidity being low, for example, at high-altitude and polar stations.

Our analysis, following the error propagation theory, resulted in a estimation of the combined CE318-T AOD standard uncertainty for each calibration method. For the daylight period $\left(u_{\mathrm{AOD}}^{\mathrm{D}}\right)$ we expect similar values to those calculated for previous sun photometer versions, ranging between 0.002 and 0.009 for reference instruments and $\sim 0.015$ for field instruments. For the night-time period, we estimated consistent $u_{\text {AOD }}^{\mathrm{N}}$ values for reference instruments of 0.0110.014 for visible channels (with the exception of $440 \mathrm{~nm}$, with values up to 0.016 for higher phase angles) and $0.012-$ 0.018 for near-IR channels. For field instruments calibrated using the Moon Ratio technique we have estimated $u_{\mathrm{AOD}}^{\mathrm{N}}$ between 0.011 and 0.019. If the new Sun Ratio technique is applied, higher uncertainties are expected: $0.012-0.015$ (0.017) for visible $(440 \mathrm{~nm})$ channels and $0.015-0.021$ for longer wavelengths. For instruments calibrated by means of the new Sun-Moon gain factor technique, the uncertainties range from 0.016 to 0.019 , in the case of using a Langleycalibrated instrument for $G$ calculation.

To summarize, the differences found in $u_{\mathrm{AOD}}^{\mathrm{N}}$ are quite low, confirming the consistency between the four calibration techniques, with maximum uncertainties of 0.017 expected in visible channels and 0.021 in the case of longer wavelengths, all of them for the low moon's illumination conditions.

We derived daytime AOD for 60 days in March, April, May and June 2014, at IZO using a CE318-T reference instrument (Langley-calibrated). We compared these observations with those extracted from independent reference instruments (CE318-AERONET and PFR) and the PSR prototype, as an assessment of the instrument performance. This AOD comparative study in the daytime reported discrepancies similar to sun photometry precision in the AERONET or GAWPFR networks $(\leq 0.01)$, also similar to the $u_{\text {AOD }}^{\mathrm{D}}$ estimated values. The nocturnal evaluation performed in Granada station using a star photometer and a secondary CE318-T showed similar low discrepancies for 870 and $500 \mathrm{~nm}$ channels $(\sim 0.01)$, within the $u_{\text {AOD }}^{\mathrm{N}}$ expected values, but higher $(\sim 0.03)$ for the $440 \mathrm{~nm}$ channel. We attributed this discrep- 
ancy to a calibration problem in the star photometer in this channel.

A subsequent coherence test for AOD at IZO using the CE318-T and CE318-AERONET master instruments was focused on the AOD daytime and night-time differences between $1 \mathrm{~h}$ after and before sunset and sunrise. The results of this coherence test match the $u^{\mathrm{N}} \mathrm{AOD}$ estimated values in the case of visible channels reasonably well at all illumination conditions. However, in the case of near-infrared channels, this consistency was only attained in high FI conditions (>90\%). This test also reflects the existence of a faint nocturnal cycle on AOD which impacts more significantly in the $1640 \mathrm{~nm}$ channel. This cycle possibly reflects a problem in instrument calibration, in night-time AOD calculation or in the lunar irradiance model, and further investigations must be carried on to properly identify and quantify the causes of the problem.

Regarding PWV, the comparison showed a good agreement between PWV CE318-T/CE318-AERONET and CE318-T/GNSS obtained in daytime and night-time conditions for any illumination condition. MB and RMSE values $<0.1 \mathrm{~cm}$ were found in the case of dry conditions, when the precision of water vapour measurements was low. We found also a slight negative bias between CE318-T and GNSS for daytime and night-time.

The final part of this paper examines two cases studies at IZO in 2014, including a sequence of dust intrusions and clean free-troposphere events (in June) and a sequence of clean conditions representative of the free troposphere (in March). These two cases showed that the CE318-T has sufficient accuracy to capture the diurnal cycle of aerosols and PWV associated with local and short-term atmospheric variations, important for climate studies.

Though these results reveal a good performance of CE318$\mathrm{T}$ in comparison to the current standard instruments, showing better precision in terms of instrument pointing, it is fair to admit that a definitive conclusion about CE318-T accuracy and precision must be stated after analysing several instruments. Further investigations are needed to determine the uncertainty reduction that the use of the integrated pressure sensor might suppose instead of using the hydrostatic equation and the NCEP/NCAR Reanalysis. Furthermore it is necessary to conduct a comprehensive investigation of the ROLO model used in this paper to perform a conclusive estimation of the uncertainties involved in it.

The comparable daytime and night-time measurements also permit nocturnal aerosol information to be included in the existing databases. It is of crucial importance for monitoring aerosol transport, especially in high-latitude locations, given the extended periods of darkness during winter, to study the effect of aerosol particles on cloud lifetime or nocturnal coverage, and for detecting the sharp changes that aerosol concentration may experience in term of hours during dust events.
To conclude, these results demonstrate the capability of the new CE318-T for monitoring aerosols and atmospheric water vapour, although further investigations must be carried out to confirm them at different locations, in a wider range of the moon's illumination and cycles and using different CE318-T photometers. These results also suggest that there may be new applications for this new CE318-T, such as moon irradiance estimation under pristine skies in highaltitude and polar stations.

Acknowledgements. This work has been developed within the framework of the activities of the World Meteorological Organization (WMO) Commission for Instruments and Methods of Observations (CIMO) Izaña Testbed for Aerosols and Water Vapor Remote Sensing Instruments. The Granada GNSS station belongs to the Instituto Andaluz de Geofísica. The AERONET sun photometers at Izaña have been calibrated within the AERONETEurope TNA, supported by the European Community-Research Infrastructure Action under the FP7 ACTRIS grant agreement no. 262254. The GAW-PFR network for AOD at WMO-GAW global observatories has been implemented by the World Optical Depth Research and Calibration Center (WORCC). This work has also been supported by the Andalusia regional government through projects P12-RNM-2409 and P10-RNM-6299, by the Spanish Ministry of Science and Technology through project CGL2013-45410-R; and finally by the EU through ACTRIS project (EU INFRA-2010-1.1.16-262254). The authors wish to thank to Ángel Gómez Peláez and Alberto Redondas for assisting the authors with the instrument's uncertainty estimation.

Edited by: V. Amiridis

\section{References}

Angström, A. K.: On the atmospheric transmission of sun radiation and on the dust in the air, Geogr. Ann. A, 12, 130-159, 1929.

Ansmann, A., Wagner, F., Althausen, D., Müller, D., Herber, A., and Wandinger, U.: European pollution outbreaks during ACE 2: Lofted aerosol plumes observed with Raman lidar at the Portuguese coast, J. Geophys. Res., 106, 20725-20733, 2001.

Baibakov, K., O’Neill, N. T., Ivanescu, L., Duck, T. J., Perro, C., Herber, A., Schulz, K.-H., and Schrems, O.: Synchronous polar winter starphotometry and lidar measurements at a High Arctic station, Atmos. Meas. Tech., 8, 3789-3809, doi:10.5194/amt-83789-2015, 2015.

Barreto, A., Cuevas, E., Damiri, B., Guirado, C., Berkoff, T., Berjón, A. J., Hernández, Y., Almansa, F., and Gil, M.: A new method for nocturnal aerosol measurements with a lunar photometer prototype, Atmos. Meas. Tech., 6, 585-598, doi:10.5194/amt-6-585-2013, 2013a.

Barreto, A., Cuevas, E., Damiri, B., Romero, P. M., and Almansa, F.: Column water vapor determination in night period with a lunar photometer prototype, Atmos. Meas. Tech., 6, 2159-2167, doi:10.5194/amt-6-2159-2013, 2013b.

Barreto, A., Cuevas, E., Mortier, A., Goloub, P., Podvin, T., Blarel, L., Choliy, V., and Hernández, Y.: Nighttime characterization of 
$\mathrm{AOD}$ and water vapor using lunar photometry, Synergies with $\mathrm{Li}-$ dar technique, WMO-TECO/CIMO-16, Commission for Instruments and Methods of Observations (CIMO), 7-9 July 2014, St. Petersburg, Russia, 2014a.

Barreto, A., Cuevas, E., Pallé, P., Romero, P. M., Guirado, C., Wehrli, C. J., and Almansa, F.: Recovering long-term aerosol optical depth series (1976-2012) from an astronomical potassiumbased resonance scattering spectrometer, Atmos. Meas. Tech., 7, 4103-4116, doi:10.5194/amt-7-4103-2014, 2014b.

Berk, A., Anderson, G. P., Bernstein, L. S., Acharya, P. K., Dothe, H., Matthew, M. W., Adler-Golden, S. M., Chetwynd, J. H. J., Richtsmeier, S. C., Pukall, B., Allred, C. L., Jeong, L. S., and Hoke, M. L..: MODTRAN4 Radiative Transfer Modelling for Atmospheric Correction, SPIE Proceeding on Optical Spectroscopic Techniques and Instrumentation for Atmospheric and Space Research, III, 3756, 348-353, 1999.

Berkoff, T. A., Sorokin, M., Stone, T., Eck, T. F., Hoff, R., Welton, E., and Holben, B.: Nocturnal aerosol optical depth measurements with a small-aperture automated photometer using the moon as a light source, J. Atmos. Ocean. Tech., 28, 1297-1306, doi:10.1175/JTECH-D-10-05036.1, 2011.

Bravo-Aranda, J. A., Titos, G., Granados-Muñoz, M. J., GuerreroRascado, J. L., Navas-Guzmán, F., Valenzuela, A., Lyamani, H., Olmo, F. J., Andrey, J., and Alados-Arboledas, L.: Study of mineral dust entrainment in the planetary boundary layer by lidar depolarisation technique, Tellus B, 67, 26180, doi:10.3402/tellusb.v67.26180, 2015.

Bruegge, C. J., Conel, J. E., Green, R. O., Margolis, J. S., Holm, R. G., and Toon, G.: Water vapor column abundances retrievals during FIFE, J. Geophys. Res., 97, 18759-18768, 1992.

Campbell, J. R., Hlavka, D. L., Welton, E. J., Flynn, C. J., Turner, D. D., Spinhirne, J. D., Scott, V. S., and Hwang, I. H.: Full-time, Eye-Safe Cloud and Aerosol Lidar Observation at Atmospheric Radiation Measurement Program Sites: Instrument and Data Processing, J. Atmos. Ocean. Tech., 19, 431-442, 2002.

Chaikovsky, A., Dubovik, O., Goloub, P., Tanré, D., Pappalardo, G.,Wandinger, U., Chaikovskaya, L., Denisov, S., Grudo, Y., Lopatsin, A., Karol, J., Lapyonok, T., Korol, M., Osipenko, F., Savitski, D., Slesar, A., Apituley, A., Alados-Arboledas, L., Binietoglou, I., Kokkalis, P., Granados-Muñoz, M. J., Papayannis, A., Perrone, M. R., Pietruczuk, A., Pisani, G., Rocadenbosch, F., Sicard, M., De Tomasi, F., Wagner, J., and Wang, X.: Algorithm and software for the retrieval of vertical aerosol properties using combined lidar/radiometer data: dissemination in EARLINET, Reviewed Revised Papers of the 26th International Laser Radar Conference, 25-29 June 2012, Porto Heli, Greece, Paper SO309, 2012.

Cuesta, J., Flamant, H. P., and Flamant, C.: Synergetic technique combining elastic backscatter lidar data and sunphotometer AERONET inversion for retrieval by layer of aerosol optical and microphysical properties, Appl. Optics, 47, 4598-4611, 2008.

Cuevas, E., González, Y., Rodríguez, S., Guerra, J. C., GómezPeláez, A. J., Alonso-Pérez, S., Bustos, J., and Milford, C.: Assessment of atmospheric processes driving ozone variations in the subtropical North Atlantic free troposphere, Atmos. Chem. Phys., 13, 1973-1998, doi:10.5194/acp-13-1973-2013, 2013.

Cuevas, E., Camino, C., Benedetti, A., Basart, S., Terradellas, E., Baldasano, J. M., Morcrette, J. J., Marticorena, B., Goloub,
P., Mortier, A., Berjón, A., Hernández, Y., Gil-Ojeda, M., and Schulz, M.: The MACC-II 2007-2008 reanalysis: atmospheric dust evaluation and characterization over northern Africa and the Middle East, Atmos. Chem. Phys., 15, 3991-4024, doi:10.5194/acp-15-3991-2015, 2015.

Dach, R., Hugentobler, U., Fridez, P., and Meindl, M.: Bernese GPS Software Version 5.0, Astronomical Institute, University of Bern, Switzerland, available at: http://www.bernese.unibe.ch/docs50/ DOCU50.pdf (last access: January 2015), 2007.

Eck, T., Holben, B., Reid, J. S., Dubovik, O., Smirnov, A., O'Neill, N. T., Slutsker, I., and Kinne, S.: Wavelength dependence of the optical depth of biomass burning urban and desert dust aerosols, J. Geophys. Res., 104, 31333-31349, doi:10.1029/1999JD900923, 1999.

Fernald, F. G.: Analysis of atmospheric lidar observations - Some comments, Appl. Optics, 23, 652-653, 1984.

Forster, P., Ramaswamy, V., Artaxo, P., Berntsen, T., Betts, R., Fahey, D. W., Haywood, J., Lean, J., Lowe, D. C., Myhre, G., Nganga, J., Prinn, R., Raga, G., Schulz, M., and Van Dorland, R.: Changes in Atmospheric Constituents and in Radiative Forcing, in: Climate Change 2007: The Physical Science Basis. Contribution of Working Group I to the Fourth Assessment Report of the Intergovernmental Panel on Climate Change, edited by: Solomon S., Qin, D., Manning, M., Chen, Z., Marquis, M., Averyt, K. B., Tignor, M., and Miller, H. L., Cambridge University Press, Cambridge, UK and New York, NY, USA, 129-234, 2007.

Granados-Muñoz, M. J., Guerrero-Rascado, J. L., Bravo-Aranda, J. A., Navas-Guzmán, F., Valenzuela, A., Lyamani, H., Chaikovsky, A., Wandinger, U., Ansmann, A., Dubovik, O., Grudo, J. O., and Alados-Arboledas, L.: Retrieving aerosol microphysical properties by Lidar Radiometer Inversion Code (LIRIC) for different aerosol types, J. Geophys. Res.-Atmos., 119, 4836-4858, 2014.

Gröbner, J., Kouremeti, N., de Coulon, E., Dürig, F., Gyo, M., Soder, R., and Waser, D.: Spectroradiometer for Spectral Aerosol Optical Depth and Solar Irradiance Measurements, Annual Report PMOD, p. 13, 2012, available at: http://www.pmodwrc. ch/annual_report/annualreport2012.pdf (last access: May 2015), 2012.

Guerrero-Rascado, J. L., Olmo, F. J., Avilés-Rodríguez, I., NavasGuzmán, F., Pérez-Ramírez, D., Lyamani, H., and Alados Arboledas, L.: Extreme Saharan dust event over the southern Iberian Peninsula in september 2007: active and passive remote sensing from surface and satellite, Atmos. Chem. Phys., 9, 84538469, doi:10.5194/acp-9-8453-2009, 2009.

Gueymard, C.: The sun's total and spectral irradiance for solar energy applications and solar radiation models, Sol. Energy, 76, 423-453, doi:10.1016/j.solener.2003.08.039, 2003.

Guirado, C., Cuevas, E., Cachorro, V. E., Toledano, C., AlonsoPérez, S., Bustos, J. J., Basart, S., Romero, P. M., Camino, C., Mimouni, M., Zeudmi, L., Goloub, P., Baldasano, J. M., and de Frutos, A. M.: Aerosol characterization at the Saharan AERONET site Tamanrasset, Atmos. Chem. Phys., 14, 1175311773, doi:10.5194/acp-14-11753-2014, 2014.

JCGM: JCGM 100:2008, GUM 1995 with Minor Corrections, Evaluation of Measurement Data - guide to the Expression of Uncertainty in Measurement, Joint Committee for Guides in Metrology, Member organizations: BIPM, IEC, IFCC, ILAC, ISO, IUPAC, IUPAP, and OIML, 2008. 
Halthore, R. N., Eck, T. F., Holben, B. N., and Markham, B. L.: Sun photometric measurements of atmospheric water vapor column abundance in the 940-nm band, J. Geophys. Res., 102, 43434352, 1997.

Herber, A., Thomason, L. W., Gernandt, H., Leiterer, U., Nagel, D., Schulz, K.-H., Kaptur, J., Albrecht, T., and Notholt, J.: Continuous day and night aerosol optical depth observations in the Arctic between 1991 and 1999, J. Geophys. Res.-Atmos., 107, AAC6.1-AAC6.13, doi:10.1029/2001JD000536, 2002.

Hoffmann, A., Ritter, C., Stock, M., Shiobara, M., Lampert, A., Maturilli, M., Orgis, T., Neuber, R., and Herber, A.: Ground-based lidar measurements from Ny-Ålesund during ASTAR 2007, Atmos. Chem. Phys., 9, 9059-9081, doi:10.5194/acp-9-9059-2009, 2009.

Holben, B. N., Eck, T. F., Slutsker, I., Tanré, D., Buis, J. P., Setzer, A., Vermote, E., Reagan, J. A., Kaufman, Y. J., Nakajima, T., Lavenu, F., Jankowiak, I., and Smirnov A.: AERONET - A federated instrument network and data archive for aerosol characterization, Remote Sens. Environ., 66, 1-16, 1998.

Holben, B. N., Tanré, D., Smirnov, A., Eck, T. F., Slutsker, I., Abuhassan, N., Newcomb, W. W., Schafer, J. S., Chatenet, B., Lavenu, F., Kaufman, Y. J., Vande Castle, J., Setzer, A., Markham, B., Clark, D., Frouin, R., Halthore, R., Karneli, A., O’Neill, N. T., Pietras, C., Pinker, R. T., Voss, K., and Zibordi, G.: An emerging ground-based aerosol climatology: Aerosol Optical Depth from AERONET, J. Geophys. Res.-Atmos., 106, 12067-12097, doi:10.1029/2001JD900014, 2001.

Kaufman, Y., Tanré, D., and Boucher, O.: A satellite view of aerosols in the climate system, Nature, 419, 215-223, 2002.

Kaufman Y. J., Gitelson, A., Karnieli, A., Ganor, E., and Fraser, R. S.: Size distribution and phase function of aerosol particles retrieved from sky brightness measurements, J. Geophy. Res.Atmos., 99, 10331-10356, 1994.

Kazadzis, S., Veselovskii, I., Amiridis, V., Gröbner, J., Suvorina, A., Nyeki, S., Gerasopoulos, E., Kouremeti, N., Taylor, M., Tsekeri, A., and Wehrli, C.: Aerosol microphysical retrievals from precision filter radiometer direct solar radiation measurements and comparison with AERONET, Atmos. Meas. Tech., 7, 20132025, doi:10.5194/amt-7-2013-2014, 2014.

Kieffer, H. H. and Stone, T. C.: The spectral irradiance of the moon, Astron. J., 129, 2887-2901, 2005.

Klett, J. D.: Inversion with variable backscatter/extinction ratios, Appl. Opt., 11, 1638-1643, 1985.

Li, Z., Blarel, L., Podvin, T., Goloub, P., Buis, J. P., and Morel, J. P.: Transferring the calibration of direct solar irradiance to diffusesky radiance measurements for Cimel sun-sky radiometers, Appl. Opt., 47, 1368-1377, 2008.

Lopatin, A., Dubovik, O., Chaikovsky, A., Goloub, P., Lapyonok, T., Tanré, D., and Litvinov, P.: Enhancement of aerosol characterization using synergy of lidar and sun-photometer coincident observations: the GARRLiC algorithm, Atmos. Meas. Tech., 6, 2065-2088, doi:10.5194/amt-6-2065-2013, 2013.

Lyamani, H., Olmo, F. J., and Alados-Arboledas, L.: Physical and optical properties of aerosols over an urban location in Spain: seasonal and diurnal variability, Atmos. Chem. Phys., 10, 239254, doi:10.5194/acp-10-239-2010, 2010.

Lyamani, H., Fernández-Gálvez, J., Pérez-Ramírez, D., Valenzuela, A., Antón, M., Alados, I., Titos, G., Olmo, F. J., and AladosArboledas, L.: Aerosol properties over two urban sites in South
Spain during an extended stagnation episode in winter season, Atmos. Environ., 62, 424-432, 2012.

Myhre, G.: Consistency Between Satellite-Derived and Modeled Estimates of the Direct Aerosol Effect, Science 325, 187-190, doi:10.1126/science.1174461, 2009.

Navas-Guzmán, F., Bravo-Aranda, J. A., Guerrero-Rascado, J. L., Granados-Muñoz, M. J., and Alados-Arboledas, L.: Statistical analysis of aerosol optical properties retrieved by Raman lidar over Southeastern Spain, Tellus B, 65, 21234, doi:10.3402/tellusb.v65i0.21234, 2013.

Nyeki, S., Gröbner, J., and Wehrli, C.: Ground-based aerosol optical depth inter-comparison campaigns at European EUSAAR supersites, AIP Conf. Proc., 1531, p. 584, doi:10.1063/1.4804837, 2013.

Ortiz de Galisteo, J. P., Toledano, C., Cachorro, V. E., and Torres, B.: Improvement in PWV estimation from GPS due to the absolute calibration of antenna phase center variation, GPS Solut., 14, 389-395, doi:10.1007/s10291-010-0163-y, 2010.

Pahlow, M., Müller, D., Tesche, M., Eichler, H., Feingold, G., Eberhard, W. L., and Cheng, Y.: Retrieval of aerosol properties from combined multiwavelength lidar and Sun photometer measurements, Appl. Opt., 45, 7429-7442, doi:10.1364/AO.45.007429, 2006.

Pérez-Ramírez, D., Ruiz, B., Aceituno, J., Olmo, F. J., and AladosArboledas, L.: Application of Sun/star photometry to derive the aerosol optical depth, Int. J. Remote Sens., 29, 5113-5132, doi:10.1080/01431160802036425, 2008a.

Pérez-Ramírez, D., Aceituno, J., Ruiz, B., Olmo, F. J., and AladosArboledas, L.: Development and calibration of a star-photometer to measure the aerosol optical depth: Smoke observations at a high mountain site, Atmos. Environ., 42, 2733-2738, $2008 \mathrm{~b}$.

Pérez-Ramírez, D., Lyamani, H., Olmo, F. J., and AladosArboledas, L.: Improvements in star photometry for aerosol characterizations, J. Aerosol Sci., 42, 737-745, doi:10.1016/j.jaerosci.2011.06.010, 2011.

Pérez-Ramírez, D., Lyamani, H., Olmo, F. J., Whiteman, D. N., Navas-Guzmán, F., and Alados-Arboledas, L.: Cloud screening and quality control algorithm for star photometer data: assessment with lidar measurements and with all-sky images, Atmos. Meas. Tech., 5, 1585-1599, doi:10.5194/amt-5-1585-2012, 2012a.

Pérez-Ramírez, D., Lyamani, H., Olmo, F. J., Whiteman, D. N., and Alados-Arboledas, L.: Columnar aerosol properties from sunand-star photometry: statistical comparisons and day-to-night dynamic, Atmos. Chem. Phys., 12, 9719-9738, doi:10.5194/acp12-9719-2012, $2012 b$.

Pérez-Ramírez, D., Veselovskii, I., Whiteman, D. N., Suvorina, A., Korenskiy, M., Kolgotin, A., Holben, B., Dubovik, O., Siniuk, A., and Alados-Arboledas, L.: High temporal resolution estimates of columnar aerosol microphysical parameters from spectrum of aerosol optical depth by linear estimation: application to long-term AERONET and star-photometry measurements, Atmos. Meas. Tech., 8, 3117-3133, doi:10.5194/amt-8-3117-2015, 2015.

Rodríguez, S., Alastuey, A., Alonso-Pérez, S., Querol, X., Cuevas, E., Abreu-Afonso, J., Viana, M., Pérez, N., Pandolfi, M., and de la Rosa, J.: Transport of desert dust mixed with North African industrial pollutants in the subtropical Saharan Air Layer, At- 
mos. Chem. Phys., 11, 6663-6685, doi:10.5194/acp-11-66632011, 2011.

Rodríguez, S., Cuevas, E., Prospero, J. M., Alastuey, A., Querol, X., López-Solano, J., García, M. I., and Alonso-Pérez, S.: Modulation of Saharan dust export by the North African dipole, Atmos. Chem. Phys., 15, 7471-7486, doi:10.5194/acp-15-74712015, 2015.

Romero, P. M., Cuevas, E., Ramos, R., Valdés, M., and Schneider, M.: Programa de vapor de agua en columna del Centro de Investigación Atmosférica de Izaña: análisis e intercomparación de diferentes técnicas de medida, NIPO: 784-09-009-9, Agencia Estatal de Meteorología, Ministerio de Medio Ambiente, y Medio Rural y Marino, Madrid, Spain, 2009.

Sasano, Y., Browell, E. V., and Ismail, S.: Error caused by using a constant extinction backscattering ratio in the lidar solution, Appl. Optics, 24, 3929-3932, 1985.

Schmid, B., Thome, K. J., Demoulin, P., Peter, R., Mätzler, C., and Sekler, J.: Comparison of modeled and empirical approaches for retrieving columnar water vapor from solar transmittance measurements in the 0.94- $\mu$ m region, J. Geophys. Res., 101, 93459358, 1996.

Schmid, B., Michalsky, J., Halthore, R., Beauharnois, M., Harisson, L., Livingston, J., Russell, P., Holben, B., Eck, T., and Smirnov, A.: Comparison of aerosol optical depth from four solar radiometers during the fall 1997 ARM intensive observation period, J. Geophys. Res., 26, 2725-2728, 1999.

Schneider, M., Romero, P. M., Hase, F., Blumenstock, T., Cuevas, E., and Ramos, R.: Continuous quality assessment of atmospheric water vapour measurement techniques: FTIR, Cimel, MFRSR, GPS, and Vaisala RS92, Atmos. Meas. Tech., 3, 323338, doi:10.5194/amt-3-323-2010, 2010.

Smirnov, A., Holben, B. N., Slutsker, I., Welton, E, J., and Formenti, P.: Optical properties of Saharan dust during ACE 2, J. Geophys. Res., 103, 28079-28092, doi:10.1029/98JD01930, 1998.

Spinhirne, J. D., Rall, J. A. R., and Scott, V. S.: Compact Eye Safe Lidar Systems, Rev. Laser Eng., 23, 112-118, 1995.

Stocker, T. F., Qin, D., Plattner, G.-K., Tignor, M., Allen, S. K., Boschung, J., Nauels, A., Xia, Y., Bex, V., and Midgley, P. M.: Climate Change 2013: The Physical Science Basis. Contribution of Working Group I to the Fifth Assessment Report of the Intergovernmental Panel on Climate Change, Cambridge University Press, Cambridge, UK and New York, NY, USA, 1535 pp., doi:10.1017/CBO9781107415324, 2013.

Suparta, W., Mohd. Ali, M. A., Yatim, B., and Fraser, G. J.: Analysis of GPS-sensed atmospheric water vapour variability and its response to the terrestrial winds over Antarctica, Phys. Chem. Earth, 34, 72-87, 2009.

Tesche, M., Müller, D., Ansmann, A., Hu, M., and Zhang, Y.: Retrieval of microphysical properties of aerosol particles from one-wavelength Raman lidar and multiwavelength sun photometer observations, Atmos. Environ., 42, 6398-6404, doi:10.1016/j.atmosenv.2008.02.014, 2008.
Titos, G., Lyamani, H., Pandolfi, M., Alastuey, A., and AladosArboledas, L.: Identification of fine (PM1) and coarse (PM10-1) sources of particulate matter in an urban environment, Atmos. Environ., 89, 593-602, 2014.

Toledano, C., Cachorro, V. E., Berjón, de Frutos, A. M., Sorribas, M., de la Morena, B. A., and Goloub, P.: Aerosol optical depth and Angström exponent climatology at El Arenosillo AERONET site (Huelva, Spain), Q. J. Roy. Meteorol. Soc., 133, 795-807, doi:10.1002/qj.54, 2007.

Tomasi, C., Kokhanovsky, A. A., Lupi, A., Ritter, C., Smirnov, A., O’Neill, N. T., Stone, R. S., Holben, B. N., and Nyeki, S.: Aerosol remote sensing in polar regions, Earth-Sci. Rev., 140, 108-157, doi:10.1016/j.earscirev.2014.11.001, 2015.

Valenzuela, A., Olmo, F. J., Lyamani, H., Antón, M., Quirantes, A., and Alados-Arboledas, L.: Classification of aerosol radiative properties during African desert dust intrusions over southeastern Spain by sector origins and cluster analysis, J. Geophys. Res.Atmos., 117, D06214, doi:10.1029/2011JD016885, 2012.

Wagner, J., Ansmann, A., Wandinger, U., Seifert, P., Schwarz, A., Tesche, M., Chaikovsky, A., and Dubovik, O.: Evaluation of the Lidar/Radiometer Inversion Code (LIRIC) to determine microphysical properties of volcanic and desert dust, Atmos. Meas. Tech., 6, 1707-1724, doi:10.5194/amt-6-1707-2013, 2013.

Wehrli, C.: Calibrations of filter radiometers for determination of atmospheric optical depth, Metrología, 37, 419-422, 2000.

Welton E. J. and Campbell J. R.: Micropulse Lidar Signals: Uncertainty Analysis, J. Atmos. Ocean. Tech., 19, 2089-2094, 2002.

Wehrli, C.: GAW-PFR: A network of Aerosol Optical Depth observations with Precision Filter Radiometers, in: WMO/GAW Experts workshop on a global surface based network for long term observations of column aerosol optical properties, GAW Report No. 162, WMO TD No. 1287, 2005.

WMO/GAW aerosol measurements procedures guidelines and recommendations, WMO report no. 153, TD No. 1178, September 2003.

WMO/GAW Experts workshop on a global surface-based network for long term observations of column aerosol optical properties, edited by: Baltensperger, U., Barrie, L., and Wehrli, C., GAW No. 162, WMO/TD-No. 1287, 2005.

Wu, P., Hamada, J.-I., Mori, S., Tauhid, Y. I., Yamanaka, M. D., and Kimura, F.: Diurnal Variation of Precipitable Water over a Mountainous Area of Sumatra Island, J. Appl. Meteorol., 42, 1107$1115,2003$. 